\title{
Modulating the lithiophilicity at electrode/electrolyte interface for high-energy Li-metal batteries
}

\author{
Cai-Cai Li ${ }^{1,2, \#,}$, Xu-Sheng Zhang ${ }^{1,2, \#,}$, Yu-Hui Zhu ${ }^{2, \#}$, Ying Zhang ${ }^{1}$, Sen Xin ${ }^{1,2}$, Li-Jun Wan ${ }^{1,2}$, Yu-Guo Guo ${ }^{1,2}$ \\ ${ }^{1}$ CAS Key Laboratory of Molecular Nanostructure and Nanotechnology, CAS Research/Education Center for Excellence in \\ Molecular Sciences, Beijing National Laboratory for Molecular Sciences (BNLMS), Institute of Chemistry, Chinese Academy of \\ Sciences (CAS), Beijing 100190, China. \\ ${ }^{2}$ University of Chinese Academy of Sciences, Beijing 100049, China. \\ \#Authors contributed equally.
}

Correspondence to: Dr. Ying Zhang, CAS Key Laboratory of Molecular Nanostructure and Nanotechnology, CAS Research/Education Center for Excellence in Molecular Sciences, Beijing National Laboratory for Molecular Sciences (BNLMS), Institute of Chemistry, Chinese Academy of Sciences (CAS), No. 2 of Zhongguancun North First Street, Haidian District, Beijing 100190, China. E-mail: yzhang@iccas.ac.cn; Prof. Sen Xin, CAS Key Laboratory of Molecular Nanostructure and Nanotechnology, CAS Research/Education Center for Excellence in Molecular Sciences, Beijing National Laboratory for Molecular Sciences (BNLMS), Institute of Chemistry, Chinese Academy of Sciences (CAS), No. 2 of Zhongguancun North First Street, Haidian District, Beijing 100190, China; University of Chinese Academy of Sciences, No.19 (A) of Yuquan Road, Shijingshan District, Beijing 100049, China. E-mail: xinsen08@iccas.ac.cn

How to cite this article: Li CC, Zhang XS, Zhu YH, Zhang Y, Xin S, Wan LJ, Guo YG. Modulating the lithiophilicity at electrode/electrolyte interface for high-energy Li-metal batteries. Energy Mater 2021;1:100017.

https://dx.doi.org/10.20517/energymater.2021.21

Received: 3 Nov 2021 First Decision: 17 Nov 2021 Revised: 9 Dec 2021 Accepted: 14 Dec 2021 Published: 31 Dec 2021

Academic Editor: Yuping Wu Copy Editor: Xi-Jun Chen Production Editor: Xi-Jun Chen

\begin{abstract}
Lithium-metal anodes show significant promise for the construction of high-energy rechargeable batteries due to their high theoretical capacity (3860 $\mathrm{mAh}^{-1}$ ) and low redox potential (-3.04 $\mathrm{V}$ vs. a standard hydrogen electrode). When Li metal is used with conventional liquid and solid electrolytes, the poor lithiophilicity of the electrolyte results in an unfavorable parasitic reaction and uneven distribution of $\mathrm{Li}^{+}$flux at the electrode/electrolyte interface. These issues result in limited cycle life and dendrite problems associated with the Li-metal anode that can lead to rapid performance fade, failure and even safety risks of the battery. The lithiophilicity at the anode/electrolyte interface is important for the stable and safe operation of rechargeable Li-metal batteries. In this review, several factors that affect the lithiophilicity of electrolytes are discussed, including surface energy, roughness and chemical interactions. The existing problems and the strategies for improving the lithiophilicity of different electrolytes are also discussed. This review helps to shed light on the understanding of interfacial chemistry vs. Li metal of various electrolytes and guide interfacial engineering towards the practical realization of high-energy
\end{abstract}

The Author(s) 2021. Open Access This article is licensed under a Creative Commons Attribution 4.0 International License (https://creativecommons.org/licenses/by/4.0/), which permits unrestricted use, sharing, adaptation, distribution and reproduction in any medium or format, for any purpose, even commercially, as long as you give appropriate credit to the original author(s) and the source, provide a link to the Creative Commons license, and indicate if changes were made. 
rechargeable batteries.

Keywords: Rechargeable batteries, Li-metal anodes, lithiophilicity, electrode/electrolyte interface

\section{INTRODUCTION}

Rechargeable lithium-ion batteries based on intercalation electrodes are now able to deliver a cell-level specific energy of $>300 \mathrm{Wh} \mathrm{kg}^{-1}$ to meet the power requirements of consumer electronics and automobiles. For further improving the energy density, rechargeable batteries that operate based on the use of metallic lithium as an anode material have shown promise, yet the practical realization of rechargeable Li-metal batteries is hindered by rapid failure and safety issues regarding the Li-metal anode. The unsatisfactory performance of Li-metal anodes originates from the unstable structural and chemical evolutions at the anode/electrolyte interface, which include infinite volume variation, the formation of unstable solid electrolyte interphases (SEIs) and the growth of Li dendrites. To improve the performance of Li-metal anodes, efforts have been made to regulate the chemical compositions and structures of the electrolyte ${ }^{[1-3]}$ and the Li-metal anode ${ }^{[4]}$ to reshape the $S E{ }^{[5,6]}$ and to rebuild the current collector ${ }^{[4,7-9]}$. The lithiophilicity of electrolytes at the anode/electrolyte interface was studied as it significantly affects the uniformity of Li deposition/dissolution at the interface. In the case of non-uniform Li deposition/dissolution, dendrite nucleation/formation occurs and can leads to severe performance decay ${ }^{[10-12]}$. To improve the electrochemical stability at the interface, researchers have turned to lithiophilic materials with the purpose of facilitating uniform Li nucleation ${ }^{[13]}$.

For a given material, its lithiophilicity can be modulated by adjusting the surface energy, surface roughness and chemical interactions with Li metal. Surface energy has a major impact on the lithiophilicity of the electrolyte and is highly correlated with the chemical compositions of the SEI. Surface roughness, according to the Wenzel model, can significantly influence the lithiophilicity ${ }^{[14]}$. This model follows the concept of super-wetting materials according to Su et al. ${ }^{[15]}$. Although the actual surface often deviates from the Wenzel model, modulating the surface roughness has proved to be an effective method to tune the lithiophilicity in recent decades ${ }^{[16]}$. For practical applications, roughness can be modulated by forming hierarchical micro/nanoscale structures. Wang et al. ${ }^{[17]}$ reported that Ni foils and foams exhibit different lithiophilicity for liquid Li due to their different surface morphologies. In addition to the surface energy and roughness, lithiophilicity can be regulated by introducing additional chemical interactions at the interface. For example, in solid-state Li-metal batteries, an interlayer capable of alloying with metallic $\mathrm{Li}$ is effective in improving the interfacial contact between the $\mathrm{Li}$ anode and the solid electrolyte $\mathrm{e}^{[18-23]}$.

The creation of a lithiophilic anode/electrolyte interface is desirable for the stable operation of a rechargeable Li-metal battery. In liquid-electrolyte-based Li-metal batteries, poor lithiophilicity often leads to inhomogeneous Li-ion distribution and dendrite formation ${ }^{[24]}$. A lithiophilic electrolyte helps to improve its wetting on the Li metal surface, promotes the formation of a homogeneous SEI and reduces continuous electrolyte consumption during battery cycling ${ }^{[25]}$. In solid-state Li-metal batteries, a lithiophobic interface leads to high interfacial resistance and rapid dendrite nucleation and propagation through the solid electrolyte, and therefore, accounts for the low critical current density ${ }^{[18-23]}$. To achieve optimal battery performance, the study of lithiophilicity enhancement between the $\mathrm{Li}$ anode and electrolytes is crucial.

This review aims to enrich the current understanding of lithiophilicity at the anode/electrolyte interface in liquid electrolyte-based and solid-state rechargeable Li-metal batteries [Figure 1], as well as its impact on battery performance. For liquid electrolyte-based batteries, strategies are provided to improve the interfacial 


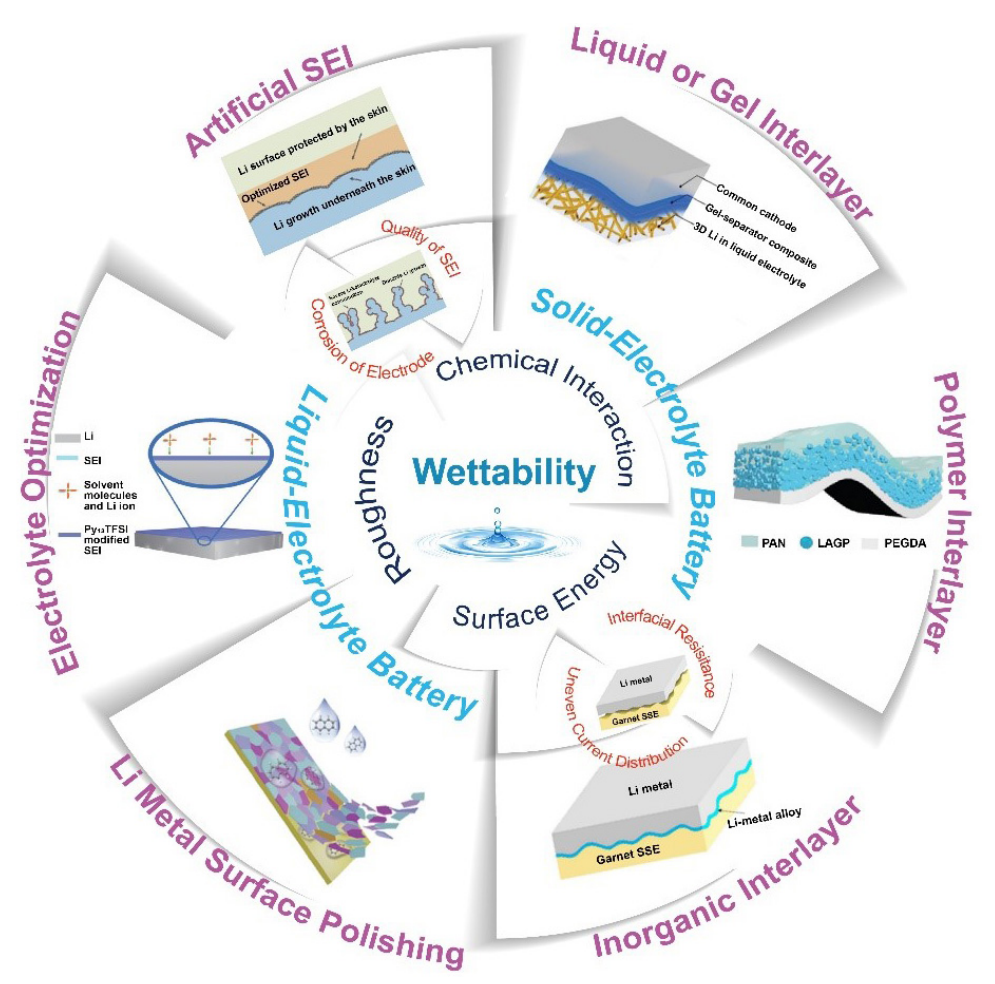

Figure 1. Schematic diagram illustrating the lithiophilicity-related studies in rechargeable Li-metal batteries with both liquid and solid electrolytes. Reproduced with permission from Ref. ${ }^{[23]}$ (Copyright 2017, American Association for the Advancement of Science), Ref. ${ }^{[26]}$ (Copyright 2016, Wiley-VCH), Ref. ${ }^{[36]}$ (Copyright 2017, American Chemical Society), Ref. ${ }^{[45]}$ (Copyright 2018, Elsevier), Ref. ${ }^{[64]}$ (Copyright 2019, Wiley-VCH) and Ref. ${ }^{[72]}$ (Copyright 2019, Wiley-VCH).

wetting, such as optimizing the compositions of the SEI and modifying the Li metal surface or the structures of the host materials. For solid-state batteries, we provide effective strategies to ameliorate the lithiophilicity of solid electrolytes so that we can address the interfacial challenges and offer insights to improve the battery performance.

\section{LITHIOPHILICITY OF LIQUID ELECTROLYTES}

The high reactivity of Li metal with electrolytes and the formation of SEI layers represent driving forces to help improve the interfacial contact between Li and electrolytes. However, the continuous reaction during the cycling process leads to excessive SEI formation and severe electrode corrosion. The construction of a stable SEI layer that possesses good lithiophilicity to Li, strong mechanical properties and stable electrochemical stability is vital to enhancing the interface and battery performance. In this section, we discuss various strategies, including the introduction of in-situ and reactive SEIs and polishing of the Li metal surface for homogeneous SEI formation. Taking advantage of the host structure with good lithiophilicity to $\mathrm{Li}$, the suppressed $\mathrm{Li}$ dendrites and volume change show a positive effect in improving the electrochemical stability of Li metal.

\section{Building lithiophilic and (electro)chemically stable SEls}

The high reactivity of metallic Li inevitably results in the decomposition of the electrolyte and SEI formation on the Li metal surface. The generated SEI is easily cracked due to the hostless volume variation of Li metal, which results in the continuous consumption of electrolytes/Li and performance fade of the anode with long-term cycling. Therefore, a lithiophilic SEI layer constructed on the surface of Li metal, which helps homogenize the distribution of nucleation sites for Li deposition and suppresses continuous 
electrolyte decomposition, is vital for boosting battery performance. At present, the strategies of SEI optimization are mainly focused on the manipulation of electrolyte chemistry and reactive artificial SEI design. The evaluation of the effectiveness of building lithiophilic and (electro)chemically stable SEIs is summarized in Table 1.

\section{Manipulation of electrolyte chemistry}

The chemical compositions of the SEI layer derived from in-situ electrolyte decomposition are highly dependent on the electrolyte components. Reasonable optimization of these components to achieve desirable strength and stability of the SEI is thus important for improving the interfacial lithiophilicity.

\section{In-situ SEIs}

It has been reported that a hybrid electrolyte consisting of an $\mathrm{N}$-propyl-N-methylpyrrolidinium bis(trifluoromethanesulfonyl)amide ( $\mathrm{P}_{13} \mathrm{TFSI}$ ) ionic liquid and ether solvents assists the formation of a stable SEI on the Li-metal anode. As a result, the Li anode shows a high coulombic efficiency (CE) of $99.1 \%$ after 360 cycles at $1 \mathrm{~mA} \mathrm{~cm}^{-2}$, which indicates the effective suppression of Li dendrites and corrosion, as shown in Figure $2 \mathrm{~A}^{[26]}$. Using pure fluoroethylene carbonate (FEC) as the solvent, Yan et al. ${ }^{[27]}$ constructed a dual-layered SEI consisting of compact organic components $\left(\mathrm{ROCO}_{2} \mathrm{Li}\right.$ and $\left.\mathrm{ROLi}\right)$ and inorganic components $\left(\mathrm{Li}_{2} \mathrm{CO}_{3}\right.$ and $\left.\mathrm{LiF}\right)$. It protected the $\mathrm{Li}$-metal anode from electrolyte corrosion and helped to regulate the Li deposition behavior. In addition, Yan et al. ${ }^{[27]}$ reported that a passivation layer could be formed via immersing Li metal in the FEC solvent. After treatment, the Li/Li-symmetric cells showed stable cycling for over $1500 \mathrm{~h}$ at $0.1 \mathrm{~mA} \mathrm{~cm}^{-2}$ in a $1 \mathrm{M} \mathrm{LiPF}_{6} /$ acetonitrile electrolyte. Different from the pure FEC solvent, Fan et al. ${ }^{[28]}$ proposed an all-fluorinated electrolyte composed of $1 \mathrm{M} \mathrm{LiPF}_{6}$ in a mixture of FEC, 3,3,3-fluoroethylmethyl carbonate and 1,1,2,2-tetrafluoroethyl-2,2,2-trifluoroethyl ether (HFE) (2:6:2 by weight). The all-fluorinated electrolyte formed a highly fluorinated interface with a thickness of 5-10 nm to prevent the electrolyte oxidation and transition metal dissolution and therefore ensure stable cyclability of the battery (when paired with $\mathrm{LiNi}_{0.8} \mathrm{Mn}_{0.1} \mathrm{Co}_{0.1} \mathrm{O}_{2}$ and $\mathrm{LiCoPO}_{4}$, the CEs are $99.93 \%$ and $99.81 \%$, respectively).

The SEI layers derived from electrolyte decomposition naturally have a benign affinity with Li metal. However, the in-situ SEIs are too fragile to adapt to the volume change of Li and prevent dendrite growth. Furthermore, they are less efficient in regulating the nucleation of Li metal. Therefore, in-situ generated SEIs are suggested to accompany other interfacial modification strategies to improve battery performance.

\section{Reactive artificial SEIs}

As a result of the poor electrochemical stability of SEIs derived from the decomposition of conventional electrolytes, artificially designed SEIs that show favorable lithiophilicity has been proposed. However, these coating layers must be chemically/electrochemically stable and mechanically strong to achieve the effect of " $1+1>2$ "[22].

With the merits of high mechanical strength and ionic conductivity and good lithiophilicity, some inorganic protective layers (such as P-based protective layers ${ }^{[30,31]}$ ) have been widely studied as protective artificial layers to inhibit Li dendrites and regulate the Li-ion transport. To acquire a stable inorganic SEI layer, Li et al. ${ }^{[32]}$ proposed an inorganic $\mathrm{Li}_{3} \mathrm{PO}_{4}$ layer by the in-situ reaction of polyphosphoric acid with $\mathrm{Li}$ metal. On the one hand, this layer could quickly spread on the electrode surface to form a smooth and uniform coating. On the other hand, the uniform $\mathrm{Li}_{3} \mathrm{PO}_{4}$ SEI layer exhibits high chemical stability without breakage/repair during the Li deposition/dissolution process [Figure $2 \mathrm{~B}]^{[32]}$. Using the same soaking method, Guo et al. ${ }^{[33]}$ prepared a $\mathrm{Li}_{3} \mathrm{PO}_{4}$ layer on the Li-metal anode of a Li-oxygen battery. With the 
Table 1. Summary of the improvement of lithiophilicity in liquid electrolytes

\begin{tabular}{|c|c|c|c|c|c|c|c|}
\hline \multicolumn{8}{|c|}{ Lithiophilic and (electro)chemically stable SEI } \\
\hline Strategy & Ref. & Method & $\begin{array}{l}\text { Interfacial resistance } \\
\text { (before cycling) }\end{array}$ & $\begin{array}{l}\text { Interfacial resistance } \\
\text { (after cycling) }\end{array}$ & $\begin{array}{l}\text { Polarized potential (after } \\
\text { cycling) }\end{array}$ & Li-Cu efficiency & Cycle life \\
\hline \multirow[t]{4}{*}{ In-situ SEI } & {$[26]$} & $\begin{array}{l}\text { lonic liquid assisted } \\
\text { SEI }\end{array}$ & $\sim 24 \Omega$ after resting $2 \mathrm{~h}$ & $\sim 32 \Omega$ after resting $48 \mathrm{~h}$ & - & $\begin{array}{l}\text { 99.1\% after } 360 \text { cycles } \\
\left(1.0 \mathrm{~mA} \mathrm{~cm}^{-2}, 3 \mathrm{~mA} \mathrm{~h} \mathrm{~cm}^{-2}\right)\end{array}$ & $\begin{array}{l}360 \text { cycles at } 0.5 \mathrm{~mA} \mathrm{~cm}^{-2} \\
1 \mathrm{~mA} \mathrm{~h} \mathrm{~cm}^{-2}\end{array}$ \\
\hline & {$[27]$} & Dual functional SEI & $\begin{array}{l}186 \Omega \text { (after a } 52 \mathrm{~h} \\
\text { standing) }\end{array}$ & $\begin{array}{l}174 \Omega \text { (after a } 52 \mathrm{~h} \\
\text { standing) }\end{array}$ & $\begin{array}{l}360 \mathrm{mV} \text { after } 25 \mathrm{~h}\left(5.0 \mathrm{~mA} \mathrm{~cm}^{-2}\right. \\
\left.0.5 \mathrm{~mA} \mathrm{~h} \mathrm{~cm}^{-2}\right)\end{array}$ & $98.3 \%\left(1.0 \mathrm{~mA} \mathrm{~cm}^{-2}\right)$ & $\begin{array}{l}90 \mathrm{~h} \text { at } 5.0 \mathrm{~mA} \mathrm{~cm}^{-2} \\
0.5 \mathrm{~mA} \mathrm{~h} \mathrm{~cm}\end{array}$ \\
\hline & [28] & $\begin{array}{l}\text { FEC derived passive } \\
\text { SEI }\end{array}$ & - & - & $\begin{array}{l}\sim 20 \mathrm{mV} \text { after } 700 \mathrm{~h}\left(1.0 \mathrm{~mA} \mathrm{~cm}^{-2}\right. \\
0.5 \mathrm{~mA} \mathrm{~h} \mathrm{~cm}\end{array}$ & - & $700 \mathrm{~h}$ at $0.1 \mathrm{~mA} \mathrm{~cm}^{-2}, 1 \mathrm{~mA} \mathrm{h \textrm {cm } ^ { - 2 }}$ \\
\hline & [29] & $\begin{array}{l}\text { All fluorinated } \\
\text { electrolyte SEI }\end{array}$ & - & - & $\begin{array}{l}\sim 78 \mathrm{mV} \text { after } 500 \mathrm{~h}\left(0.2 \mathrm{~mA} \mathrm{~cm}^{-2}\right. \\
\left.1 \mathrm{~mA} \mathrm{~h} \mathrm{~cm}^{-2}\right) \text { Li|Cu battery }\end{array}$ & $\begin{array}{l}>99 \% \text { after } 500 \text { cycles } \\
\left(0.5 \mathrm{~mA} \mathrm{~cm}^{-2}, 2 \mathrm{~mA} \mathrm{~h} \mathrm{~cm}^{-2}\right)\end{array}$ & $\begin{array}{l}500 \mathrm{~h} \text { at } 0.2 \mathrm{~mA} \mathrm{~cm}^{-2}, 1 \mathrm{~mA} \mathrm{~h} \mathrm{~cm}^{-2} \\
\text { Li|Cu battery }\end{array}$ \\
\hline \multirow[t]{9}{*}{$\begin{array}{l}\text { Reactive } \\
\text { artificial SEI }\end{array}$} & [33] & Inorganic $\mathrm{Li}_{3} \mathrm{PO}_{4} \mathrm{SEI}$ & - & $\begin{array}{l}80 \Omega \text { after } 24 \mathrm{~h} \text { in Li|Li } \\
\text { battery }\end{array}$ & - & - & $600 \mathrm{~h}$ at $0.5 \mathrm{~mA} \mathrm{~cm}^{-2}, 1 \mathrm{~mA} \mathrm{~h} \mathrm{~cm}^{-2}$ \\
\hline & {$[35]$} & $\begin{array}{l}\text { Single-ion- } \\
\text { conducting } \mathrm{Li}_{3} \mathrm{PS}_{4} \mathrm{SEI}\end{array}$ & $20 \Omega \mathrm{cm}^{-2}$ & $5 \Omega \mathrm{cm}^{-2}$ after 10 cycles & 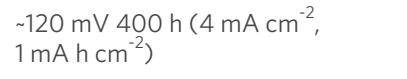 & - & $400 \mathrm{~h}$ at $4 \mathrm{~mA} \mathrm{~cm}^{-2}, 1 \mathrm{~mA} \mathrm{~h} \mathrm{~cm}^{-2}$ \\
\hline & {$[36]$} & Skin-grafting SEI & $\sim 90 \Omega$ & $130 \Omega$ after 100 cycles & $\begin{array}{l}\sim 30 \mathrm{mV}_{\text {after }} 300 \mathrm{~h}\left(0.5 \mathrm{~mA} \mathrm{~cm}^{-2}\right. \\
\left.1 \mathrm{~mA} \mathrm{~h} \mathrm{~cm}^{-2}\right)\end{array}$ & $\begin{array}{l}98.3 \% \text { after } 200 \text { cycles } \\
\left(0.5 \mathrm{~mA} \mathrm{~cm}^{-2}, 1 \mathrm{~mA} \mathrm{~h} \mathrm{~cm}^{-2}\right)\end{array}$ & $\begin{array}{l}\text { Over } 300 \mathrm{~h}^{-2} \text { at } 0.5 \mathrm{~mA} \mathrm{~cm}^{-2} \\
1 \mathrm{~mA} \mathrm{~h} \mathrm{~cm}^{-2}\end{array}$ \\
\hline & [37] & LiPAA SEI & $\sim 160 \Omega$ & $\sim 90 \Omega$ after 50 cycles & - & - & $700 \mathrm{~h} 0.5 \mathrm{~mA} \mathrm{~cm}^{-2}$ \\
\hline & {$[38]$} & $\begin{array}{l}\text { PECA-based artificial } \\
\text { SEI }\end{array}$ & $\sim 60 \Omega$ after resting 1 day & $\sim 70 \Omega$ after resting 7 days & - & - & $\begin{array}{l}\text { Capacity retention of } 93 \% \text { at } 2 \mathrm{C} \\
\text { for } 500 \text { cycles in } \mathrm{LiFePO}_{4} \mid \mathrm{Li}\end{array}$ \\
\hline & [39] & $\mathrm{Li}_{x} \mathrm{SiS}_{\mathrm{y}} /$ Nafion film & - & - & 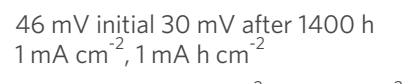 & - & $1400 \mathrm{~h}$ at $1 \mathrm{~mA} \mathrm{~cm}^{-2}, 1 \mathrm{~mA} \mathrm{~h} \mathrm{~cm}^{-2}$ \\
\hline & {$[40]$} & $\begin{array}{l}\text { LixSiSy protection } \\
\text { layer }\end{array}$ & - & - & $\sim 25 \mathrm{mV}$ at $0.1 \mathrm{~mA} \mathrm{~cm}^{-2}, 1 \mathrm{~mA} \mathrm{~h} \mathrm{~cm}^{-2}$ & - & $\begin{array}{l}2000 \mathrm{~h} \text { at } 0.1 \mathrm{~mA} \mathrm{~cm}^{-2} \\
1 \mathrm{~mA} \mathrm{~h} \mathrm{~cm}^{-2}\end{array}$ \\
\hline & {$[41]$} & Armored $\mathrm{MCl}$ film & $55 \Omega$ & $67 \Omega$ after resting $300 \mathrm{~h}$ & 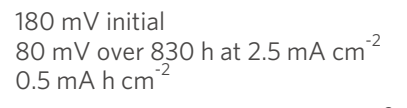 & - & $\begin{array}{l}830 \mathrm{~h} \text { at } 2.5 \mathrm{~mA} \mathrm{~cm}^{-2} \\
0.5 \mathrm{~mA} \mathrm{~h} \mathrm{~cm}^{-2}\end{array}$ \\
\hline & {$[42]$} & $\begin{array}{l}\text { PTMEG-Li/Sn alloy } \\
\text { hybrid layer }\end{array}$ & $14 \Omega$ after resting $0.5 \mathrm{~h}$ & $22 \Omega$ after resting $24 \mathrm{~h}$ & $\begin{array}{l}30 \mathrm{mV}_{\text {after }} 1000 \mathrm{~h} \text { at } 0.1 \mathrm{~mA} \mathrm{~cm}^{-2} \\
1 \mathrm{~mA} \mathrm{~h} \mathrm{~cm}^{-2}\end{array}$ & - & $\begin{array}{l}1000 \mathrm{~h} \text { at } 0.1 \mathrm{~mA} \mathrm{~cm}^{-2} \\
1 \mathrm{~mA} \mathrm{~h} \mathrm{~cm}^{-2}\end{array}$ \\
\hline
\end{tabular}

synergistic effects of DMSO, $\mathrm{LiNO}_{3}$ and $\mathrm{LiI}$, the $\mathrm{Li}_{3} \mathrm{PO}_{4}$-protected $\mathrm{Li}$ anode exhibited excellent electrochemical stability and no mossy or dendritic Li was found during the cycling process. To create a uniform SEI that binds tightly with Li metal, Pang et al. ${ }^{[34]}$ developed a single-ion-conducting $\mathrm{Li}_{3} \mathrm{PS}_{4} \mathrm{SEI}$ layer formed by soaking $\mathrm{Li}$ foil in a dimethoxyethane (DME) solution with a trace amount of electrolyte additive complex $\left(\mathrm{Li}_{2} \mathrm{~S}_{6}-\mathrm{P}_{2} \mathrm{~S}_{5}\right)$. This thin amorphous $\mathrm{Li}_{3} \mathrm{PS}_{4}$ layer had a high $\mathrm{Li}^{+}$transference number of 1 , which effectively promoted $\mathrm{Li}^{+}$transport and avoided the presence of a strong electric field to obtain a dendrite-free morphology. 

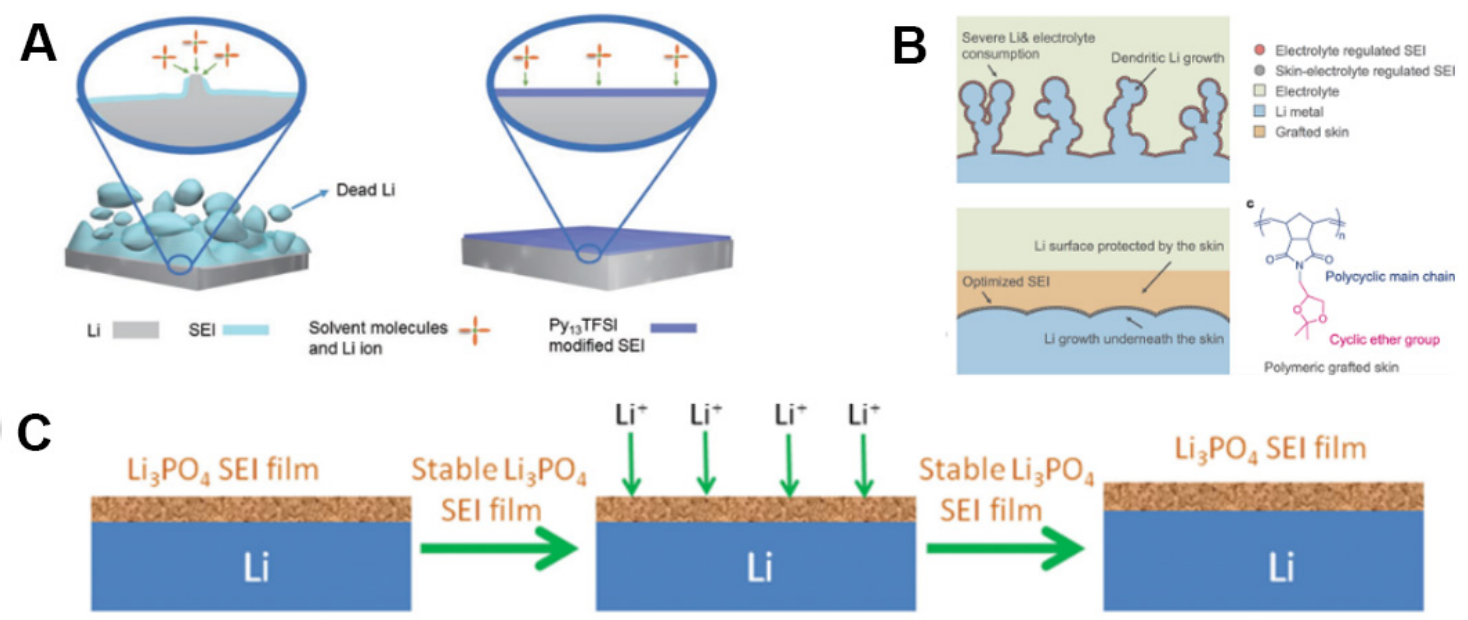

\section{$\mathrm{Li}_{3} \mathrm{PO}_{4} \mathrm{SEI}$ film}

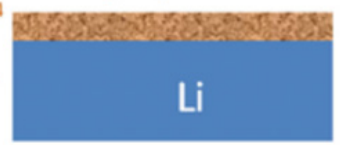

D
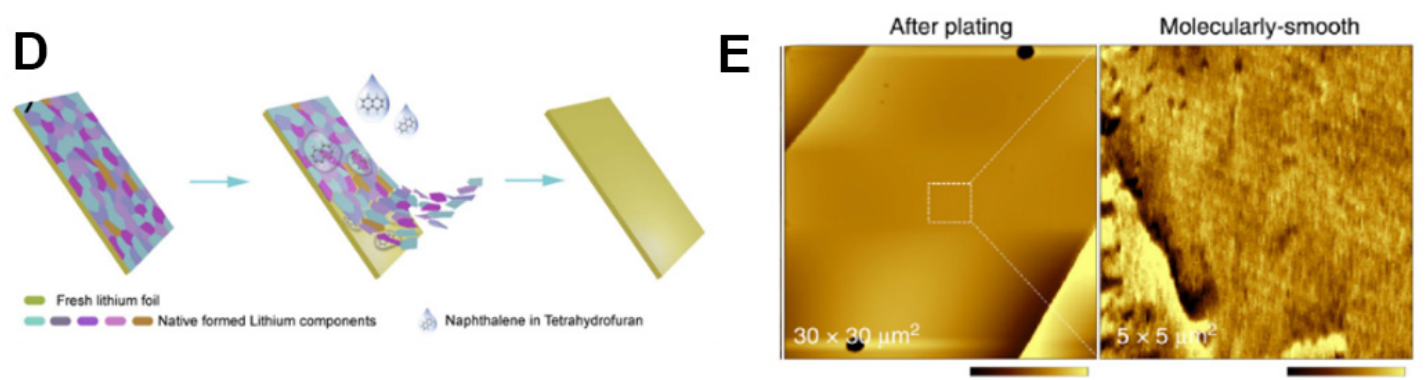

Figure 2. (A) Surface structure of Li metal in a 1,3-dioxolane (DOL), 1,2-dimethoxyethane (DME) and lithium bis(trifluoromethanesulfonyl)imide (LiTFSI) ether-based electrolyte and an optimized hybrid electrolyte by using hybrid N-propyl-Nmethylpyrrolidinium bis(trifluoromethanesulfonyl)amide (Py13TFSI) and ether electrolyte in rechargeable Li-metal batteries ${ }^{[26]}$. Copyright 2016, Wiley-VCH. (B) $\mathrm{Li}_{3} \mathrm{PO}_{4}$-modified Li metal anode exhibiting a smooth and uniform surface after Li plating/stripping ${ }^{[32]}$. Copyright 2015, Wiley-VCH. (C) Different interfacial structural characteristics of bare Li metal and Li metal coated with polymer skin ${ }^{[35]}$. Copyright 2017, American Chemical Society. (D) Preparation process of polished Li foil in a naphthalene solution ${ }^{[44]}$. Copyright 2018, Elsevier. (E) AFM characterization showing the morphology of polished Li metal surfaces after plating in the electrolyte of $1 \mathrm{M}$ lithium bis(trifluoromethanesulfonyl)imide (LiTFSI) in a mixture of dimethoxyethane/1,3-dioxolane (DME/DOL, v/v=1:1) ${ }^{[45]}$. Copyright 2018, Nature Publishing Group.

Organic protective layers are favored for their high flexibility and lithiophilicity to resist volume changes and maintain the integrity of the SEI. A skin-grafting strategy was proposed to prepare chemically and electrochemically active poly((N-2,2-dimethyl-1,3-dioxolane-4-methyl)-5-norbornene-exo-2,3-dicarboximide) on Li metal [Figure $2 \mathrm{C}]^{[35]}$. The polymer layer showed a high volume fraction of cyclic ether groups, which had good lithiophilicity and could avoid an excessive parasitic reaction between the Li metal and electrolyte. Furthermore, Li et al. ${ }^{\left[{ }^{[3]}\right]}$ designed a Li polyacrylic acid (LiPAA) SEI layer via an in-situ reaction between Li metal and PAA. Due to the high binding ability and stretchability of the LiPAA polymer, the formed SEI could effectively address the dynamic volume change of Li metal during $\mathrm{Li}$ plating/stripping by adapting and regulating the interface. Therefore, the side reactions and Li dendrite growth could be avoided and stable cycling of $700 \mathrm{~h}$ could be obtained in $\mathrm{Li} / \mathrm{Li}$-symmetric cells. Wang et al. ${ }^{[13]}$ reported a porous and lithiophilic polymer coating induced by the phase separation of polyvinylidenefluoride-polyacrylonitrile (PAN) blends, which promoted uniform Li deposition and rapid $\mathrm{Li}^{+}$diffusion.

Organic-inorganic hybrids not only have high mechanical strength (inorganic layer) but also high flexibility and lithiophilicity (organic layer), so that they provide a promise and feasible strategy to improve the interfacial stability. Based on this concept, an artificial SEI layer prepared from the in-situ polymerization of 
ethyl $\alpha$-cyanoacrylate (ECA) monomer precursors in the presence of $\mathrm{LiNO}_{3}$ additives was proposed ${ }^{[37]}$. The $\mathrm{CN}^{-}$groups from ECA and the $\mathrm{NO}_{3}^{-}$groups from $\mathrm{LiNO}_{3}$ could react with the Li metal to generate an inner inorganic nitrogenous interface layer, combined with the outer poly(ethyl $\alpha$-cyanoacrylate) (PECA) layer. This organic-inorganic protective layer could facilitate ionic conductivity and restrain the volume change caused by the Li plating/stripping process. Additionally, for Li-S batteries, Jin et al ${ }^{[38]}$ proposed a doublelayered artificial SEI-Li $\mathrm{SSiS}_{\mathrm{y}} / \mathrm{Nafion}$ composite layer, consisting of an organic lithiated Nafion layer facing towards the electrolyte and an inorganic $\mathrm{Li}_{\mathrm{x}} \mathrm{SiS}_{\mathrm{y}}$ layer facing towards the $\mathrm{Li}$ metal. The soft Nafion layer provided flexibility to maintain the structural integrity of the SEI and to prevent the shuttling of polysulfide anions. The rigid $\mathrm{Li}_{\mathrm{x}} \mathrm{SiS}_{\mathrm{y}}$ layer showed high ionic conductivity and mechanical strength to inhibit Li dendrite growth. It is noteworthy that the $\mathrm{Li}_{\mathrm{x}} \mathrm{SiS}_{\mathrm{y}}$ layer was directly grown on the Li metal surface, based on the following two in-situ reactions, so that it ensures intimate contact with the electrode ${ }^{[39]}$ :

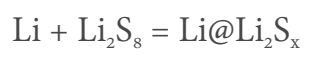

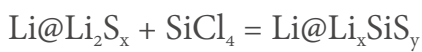

In particular, it has been reported that materials with a high bulk diffusion coefficient of $\mathrm{Li}^{+}$, such as $\mathrm{LiF} / \mathrm{Cu}^{[40]}$ and $\mathrm{Sn}^{[41]}$, are able to facilitate rapid $\mathrm{Li}^{+}$transport and protect Li metal from dendrite formation. In a recent work by Yan et al. ${ }^{[40]}$, a mixed ionic-electronic conducting interphase (MCI), consisting of LiF and $\mathrm{Cu}$, was formed on the Li metal surface through an in-situ displacement reaction between copper fluoride $\left(\mathrm{CuF}_{2}\right)$ and $\mathrm{Li}$. The MCI showed excellent Li storage ability at the grain boundaries of $\mathrm{LiF} / \mathrm{Cu}$ and a high $\mathrm{Li}^{+}$ conductivity, as well as high mechanical strength to suppress $\mathrm{Li}$ dendrite growth. The $\mathrm{LiNi}_{0.5} \mathrm{Co}_{0.2} \mathrm{Mn}_{0.3} \mathrm{O}_{2} \mid \mathrm{Li}$ cell with the MCI film was able to deliver an extremely high CE of $99.5 \%$ with a long lifespan of 500 cycles. Jiang et al. ${ }^{[4]}$ proposed a facile method to construct an artificial hybrid SEI consisting of poly(tetramethylene ether glycol) (PTMEG) and a Li/Sn alloy, which provided abundant $\mathrm{Li}^{+}$diffusion channels due to the Li vacancies in the Li/Sn alloy and a strong affinity for Li because of the abundant C-O bonds in the polymer. The treated Li-metal anode showed a much smaller contact angle $\left(27^{\circ}\right)$ with ether electrolytes than that for water $\left(70{ }^{\circ} \mathrm{C}\right)$. Therefore, the treated Li maintained good activity and capacity retention in $\mathrm{Li}-\mathrm{S}$ and $\mathrm{Li}-\mathrm{LiFePO}_{4}(\mathrm{LFP})$ full cells.

Artificial SEIs constructed on the surface of Li metal can combine the advantages of organic and inorganic materials to regulate Li-ion transport and inhibit Li dendrites and therefore exhibit better battery performance than in-situ SEIs. However, artificial SEIs still express a deficiency in flexibility and mechanical strength. More importantly, artificial SEIs do not solve the fundamental problems of Li metal, such as the huge volume change and formation of dead Li.

\section{Chemical treatment of Li metal surface}

The high reactivity of Li metal with an electrolyte easily gives rise to the formation of various surface contaminants, such as $\mathrm{Li}_{2} \mathrm{O}, \mathrm{Li}_{2} \mathrm{CO}_{3}$ and $\mathrm{LiOH}$, which usually lead to poor lithiophilicity, inhomogeneous surface morphology and SEI growth. Since these contaminants are poor electronic/ionic conductors, their accumulation on the surface of Li metal inevitably leads to high interfacial impedance ${ }^{[42]}$. Therefore, it is necessary to remove the surface contaminants from the Li metal foil before using them in rechargeable batteries.

The chemical polishing of Li metal foil has proved to be an effective method to remove the surface contaminants. For example, a macroscopically flat surface of Li metal could be obtained after pure acetone $^{[43]}$ or naphthalene solution ${ }^{[44]}[$ Figure $2 \mathrm{D}]$ treatment based on the Li-solvent reactions. However, the 
above strategies failed to provide desirable smoothness at the microscopic scale and the formed SEI was too fragile to inhibit the growth of Li dendrites. To address this problem, the electrochemical polishing method has been proposed to smooth the Li metal surface and modulate the SEI composition simultaneously. A multi-step electrochemical polishing procedure was carried out in a conventional ether electrolyte, $1 \mathrm{M}$ LiTFSI-DME/DOL ( $\mathrm{v}: \mathrm{v}=1: 1$ ), by a potentiostatic stripping and galvanostatic plating process. A primarily smooth foil surface and the initial stage of SEI formation were achieved by Li-metal dissolution and electrolyte reduction. The metallic Li deposition and further reduction of the electrolyte then worked together to heal the remaining defects and complete the SEI formation [Figure $2 \mathrm{E}]^{[45]}$. During the electrochemical polishing process, the ultra-smooth and ultra-thin SEI with alternating laminated inorganic- and organic-rich mixed multilayer structures was obtained. It is noted that fine control of the anodic stripping and cathodic plating potentials and electrolyte components and a high current density in the stripping process are necessary for determination of the smoothness of the Li metal surface and the structure of the SEI ${ }^{[46]}$.

The chemical polishing of $\mathrm{Li}$ could help remove the surface contaminants, such as $\mathrm{LiOH}, \mathrm{Li}_{2} \mathrm{CO}_{3}$ and $\mathrm{Li}_{2} \mathrm{O}$, homogenize the lithium deposition and reduce the interfacial impedance. However, these strategies could not solve the issues generated during $\mathrm{Li}$ cycling. Other modification strategies conducted on polished Li foils could help optimize the cycling performances of Li-metal batteries.

\section{Modulating the lithiophilicity of anode host materials}

A Li host material with a large specific surface area and sufficient pore volume is desired to suppress $\mathrm{Li}$ dendritic growth and accommodate Li volume change during the Li stripping/plating process. However, most host materials exhibit poor affinity to Li, which leads to uneven Li deposition. Therefore, tuning the lithiophilicity of the host materials from lithiophobic to lithiophilic is vital for the realization of nextgeneration Li-metal batteries.

\section{Chemical strategies for improving lithiophilicity}

At present, the methods for improving the lithiophilicity of host materials are mostly operated under a high vacuum, which is time-consuming and costly. Recently, a new chemical strategy has been proposed by Wang et al. ${ }^{[4]}$, which employed functional groups, such as $-\mathrm{COOH},-\mathrm{OH},-\mathrm{SO}_{3} \mathrm{H},-\mathrm{NH}_{2},-\mathrm{NH}-,-\mathrm{Si}-\mathrm{O},-\mathrm{F},-\mathrm{Cl}$, - Br and -I, or elemental additives, such as Mg, In, Ca, Sr, Ba, Sc, Y, Rh, Ir, Pd, Pt, Au, Cd, Hg, Ga, Tl, Ge, Pb, $\mathrm{As}, \mathrm{Sb}, \mathrm{Bi}, \mathrm{S}$, Se and Te, to alter the lithiophilicity of host materials. This strategy was applied based on negative Gibbs formation energies $\left(\Delta_{r} G\right)$ and newly-formed chemical bonds. Notably, they summarized the lithiophilic properties of different elements for a better understanding of the wetting behavior of molten $\mathrm{Li}$ on various substrates [Figure $3 \mathrm{~A}]^{[47]}$. For example, molten Li does not react with the elements in red (like Ti and $\mathrm{Fe}$ ) at $180-300{ }^{\circ} \mathrm{C}$; however, lithiophilic organic coatings with functional groups, such as - N, -F, -P and $\mathrm{Br}$ (given in blue) wet well with molten Li and the addition of lithiophilic elements in green (like In and $\mathrm{Mg}$ ) in molten Li also helps to improve the lithiophilicity. Therefore, it is important to understand the lithiophilicity of various substrates for molten Li, through which one can prepare ultrathin Li-metal anodes. In addition, layered reduced graphene oxide (rGO), after a spark reaction, exhibits a high lithiophilicity due to the strong binding energy between the organic functional groups of rGO (such as carbonyl and alkoxy groups) and Li metal, which helps to promote the infusion of molten Li into the rGO interlayers [Figure $3 \mathrm{~B}]^{[48]}$.

\section{Lithiophilic coatings on host materials}

Lithiophilic coating of the host materials represents another effective strategy to improve the anode performance, as the modified host plays an excellent role in regulating Li stripping/plating and provides 


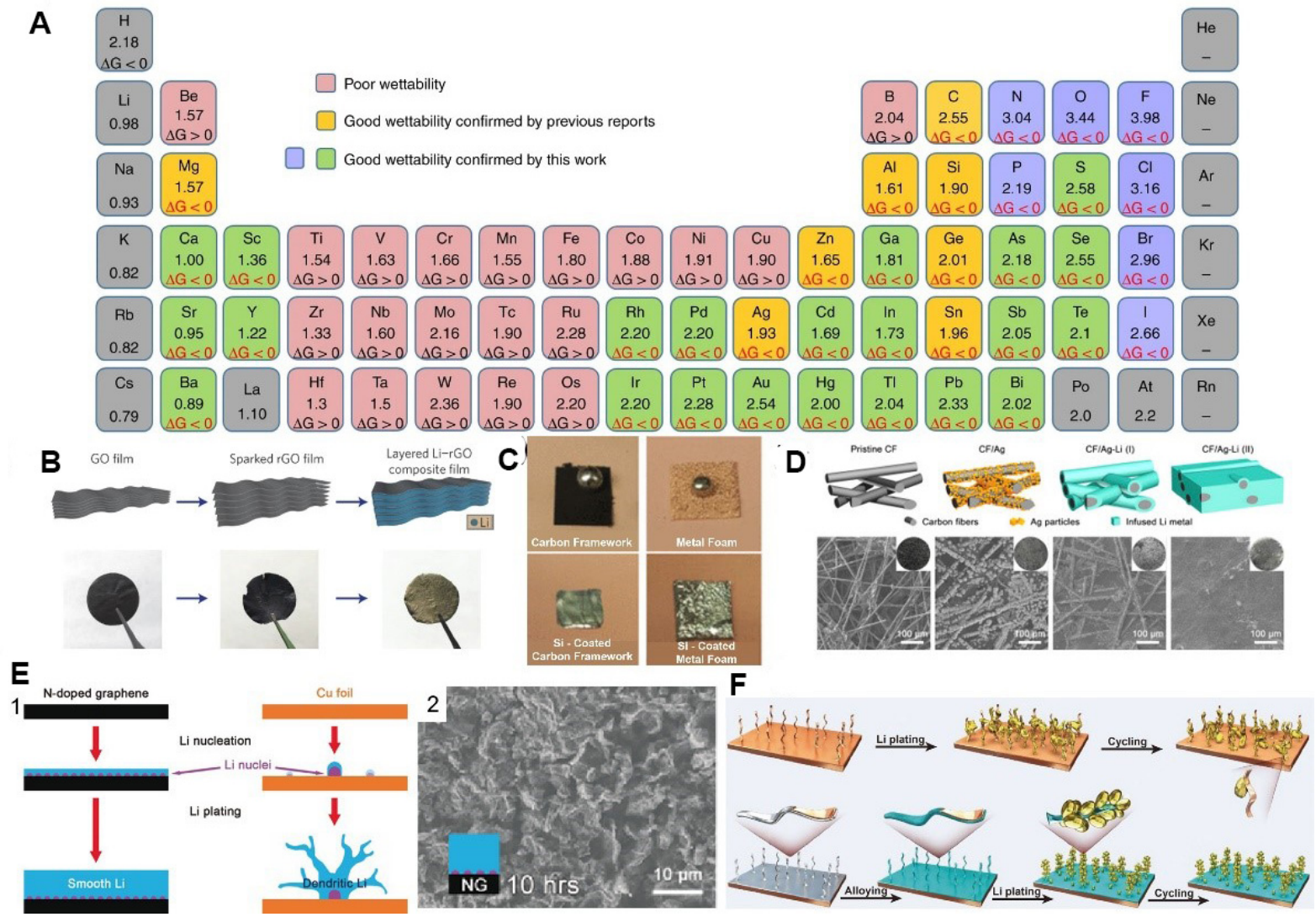

Figure 3. (A) Electronegativities and $\Delta_{\mathrm{r}} \mathrm{G}$ of various elements that are able to react with molten $\mathrm{Li}$ in the periodic table. The elements in green and blue represent those that could react with molten Li by forming new chemical bonds, which is responsible for the improved wettability, while red represents the elements that could not react with the molten $\mathrm{Li}^{[47]}$. Copyright 2019, Nature Publishing Group. (B) Fabrication of a layered Li-rGO composite film that consists of a GO film (left), a sparked rGO film (middle) and a layered Li-rGO composite film (right) ${ }^{[48]}$. Copyright 2016, Nature Publishing Group. (C) Comparison of lithiophilicity of different substrates with and without the Si coating ${ }^{[49]}$. Copyright 2016, National Academy of Sciences. (D) Schematic of synthesis process of carbon fiber CF/Ag-Li. The CF with electroplated $\mathrm{Ag}$ layer (CF/Ag), only the surface of $\mathrm{CF}$ is covered with molten $\mathrm{Li}[\mathrm{CF} / \mathrm{Ag}-\mathrm{Li}(\mathrm{I})]$ and the CF framework is completely covered by molten $\mathrm{Li}[\mathrm{CF} / \mathrm{Ag}-\mathrm{Li}(\mathrm{II})]^{[54]}$. Copyright 2018, Elsevier. (E) Different Li nucleation and plating processes on $\mathrm{N}$ doped graphene and $\mathrm{Cu}$-foil electrodes and the SEM image of Li deposits at a low current density of $0.05 \mathrm{~mA} \mathrm{~cm}^{-2}$ for $10 \mathrm{~h}^{[57]}$. Copyright 2017, Wiley-VCH. (F) Thin Al layer reacted with Li to generate a binary Li-Al alloy phase, which functioned as the lithiophilic sites to ensure homogeneous growth of $\mathrm{Li}^{[60]}$. Copyright 2017, American Chemical Society.

confinement for the suppression of the anode volume change. By coating lithiophilic Si on a threedimensional $(3 \mathrm{D})$ porous carbon matrix, the molten Li is quickly infused into a surface-modified 3D matrix ${ }^{[49]}$. Interestingly, a binary alloy phase of lithium silicide was created by the spontaneous reaction of $\mathrm{Si}$ and Li metal and therefore the low contact angle with molten Li was easily obtained [Figure $3 \mathrm{C}]^{[49]}$. Derived from natural wood, Zhang et al. ${ }^{[5]}$ demonstrated that a lithiophilic $\mathrm{ZnO}$-coated carbon matrix with unique well-aligned channels showed advantages in uniformizing Li nucleation and growth, as well as alleviating dendrite growth. In addition to Li/C-wood composites, Liu et al. ${ }^{[51]}$ found that by coating a layer of $\mathrm{ZnO}$ on a polyimide (PI) matrix, the molten Li can be quickly infused into the PI matrix. Such a design enables uniform Li stripping/plating and contributes to improved cycling stability over 500 cycles at a current density of $5 \mathrm{~mA} \mathrm{~cm}{ }^{-2}$. In addition to $\mathrm{ZnO}, \mathrm{Al}_{2} \mathrm{O}_{3}{ }^{[52]}$ and $\mathrm{SnO}_{2}{ }^{[53]}$ also show good affinity to Li metal. For example, Zhang et al. ${ }^{[54]}$ electroplated Ag on a carbon fiber (CF) framework and produced a lithiophilic coating layer that guided molten $\mathrm{Li}$ into the matrix and accounted for the dendrite-free morphology [Figure 3D]. Xu et al. ${ }^{[55]}$ developed a graphitic carbon nitrite layer $\left(\mathrm{g}-\mathrm{C}_{3} \mathrm{~N}_{4}\right)$ that was evenly coated on carbon cloth (CC). Because of the high lithiophilicity of $\mathrm{N}$ in $g-\mathrm{C}_{3} \mathrm{~N}_{4}$ and the high specific surface area of CC, 
metallic Li could be uniformly deposited into the interlayer between the $\mathrm{g}_{-} \mathrm{C}_{3} \mathrm{~N}_{4}$ layer and CC fibers. $\mathrm{Li} \mid \mathrm{Li}$ symmetric cells with $\mathrm{g}-\mathrm{C}_{3} \mathrm{~N}_{4} / \mathrm{CC}$ operated stably for over $1500 \mathrm{~h}$ with a small overpotential of $\sim 80 \mathrm{mV}$ at $2 \mathrm{~mA} \mathrm{~cm}^{-2}$.

Doping of host materials with lithiophilic species

Because of the weak lithiophilic properties of most carbon materials, many dopants have been adopted to improve the lithiophilicity between the molten Li and the host material. For example, bromide and bromide intermediates $(\mathrm{Br}, \mathrm{CuBr}$ and $\mathrm{LiBr}$ ) show high lithiophilicity, which can promote homogenous $\mathrm{Li}$ nucleation ${ }^{[56]}$. When paired with a $\mathrm{LiFePO}_{4}$ cathode, the full cells exhibit significantly improved cycling performance and a high capacity retention of $98 \%$ after 200 cycles. Furthermore, pyridinic and pyrrolic nitrogen in $\mathrm{N}$-doped graphene have been demonstrated to be effective in guiding uniform Li nucleation [Figure $3 \mathrm{E}]^{[57]}$. Chen et al. ${ }^{[58]}$ demonstrated that O- or O/B-co-doped carbon materials also help to guide uniform Li nucleation. N/P-co-doped CC is easily wetted by molten Li due to the significantly improved binding energy between $\mathrm{Li}$ and the $\mathrm{CC}^{[59]}$. A Li- $\mathrm{I}_{2}$ full battery with such a $3 \mathrm{D}$ electrode exhibited an ultralong cycle life with a high capacity of $197 \mathrm{mAh} \mathrm{g}^{-1}$ over 4000 cycles at $10 \mathrm{C}$.

\section{Alloying of anode materials}

Materials that form alloys with Li metal, such as $\mathrm{Li} / \mathrm{Al}^{\left[{ }^{[0]}\right.}$ and $\mathrm{Mg}$-doped Li-LiB alloys ${ }^{[6]}$, have been demonstrated to strongly bind with Li metal and therefore represent promising host materials. In particular, the Li-Al alloy can be generated through an in-situ electrochemical reaction and exhibits high lithiophilicity towards Li metal, so that it regulates Li nucleation and growth to enable dendrite-free plating [Figure $3 \mathrm{~F}]^{[60]}$. More importantly, the Li-Al alloy can compensate for the irreversible Li loss and extend the lifespan of the battery. The addition of $\mathrm{Mg}$ into a $\mathrm{LiB}$ alloy not only reduces the volume variation and local current density but also increases the adsorption energy of $\mathrm{Li}$ and therefore contributes to homogeneous $\mathrm{Li}^{+}$flux at the interface ${ }^{[61]}$. The proposed 3D Li-B-Mg composite anode displays a long and stable cycle life for more than $500 \mathrm{~h}$ at $0.5 \mathrm{~mA} \mathrm{~cm}^{-2}$ without a short circuit in the Li|Li symmetric cell. Wei et al. ${ }^{[62]}$ recently studied the $3{ }^{\circ} \mathrm{C}$ GaInSnZn liquid metal that is able to react with Li metal and a Li-based alloy framework can be formed on the surface of Li metal. The Li-based alloy framework tightly attaches to Li metal to provide fast $\mathrm{Li}^{+}$ diffusion, lower chemical reactivity and better lithiophilicity than pure Li.

Improving the lithiophilicity of host materials can effectively reduce the local current density and nucleation overpotential for Li deposits. The effectiveness of different anode host materials formed from different lithiophilic modulation strategies is listed in Table 2. Nevertheless, the dispersion uniformity of dopants is hindered by the complicated host structure and alloying anodes face significant synthetic difficulties due to the sensitivity of Li to temperature and atmosphere. Therefore, the performance of Li anodes has not been greatly improved in batteries at scale.

\section{LITHIOPHILICITY OF SOLID ELECTROLYTES}

Although numerous efforts have been made to improve the lithiophicility in liquid Li-metal batteries, the existence of liquid electrolytes that are highly reactive with Li metal still raises safety hazards. Replacing liquid electrolytes with solid electrolytes that possess good mechanical strength presents significant potential in addressing such safety problems and inhibiting Li dendrites. However, the poor lithiophilicity of solid electrolytes towards Li metal induces high resistance and blocks effective ion transport, which has restricted the development of solid-state Li-metal batteries. Taking advantage of the excellent lithiophilicity of liquids, gels and polymers with Li metal, the poor solid-solid contact can be changed into a benign liquid-solid or a soft solid-solid contact, which resolves this interfacial dilemma. The strategies for improving lithiophilicity in solid electrolytes are summarized in Table 3. 
Table 2. Summary of the improvement of lithiophilicity of anode host materials

\begin{tabular}{|c|c|c|c|c|c|c|c|}
\hline \multicolumn{8}{|c|}{ Modulating the lithiophilicity of anode host materials } \\
\hline Strategy & Ref. & Method & $\begin{array}{l}\text { Interfacial } \\
\text { resistance (before } \\
\text { cycle) }\end{array}$ & $\begin{array}{l}\text { Interfacial } \\
\text { resistance (after } \\
\text { cycle) }\end{array}$ & $\begin{array}{l}\text { Polarized potential (after } \\
\text { cycling) }\end{array}$ & Li-Cu efficiency & Cycle life \\
\hline $\begin{array}{l}\text { Chemical strategies for } \\
\text { improving the lithiophilicity }\end{array}$ & [49] & $\begin{array}{l}\text { rGO layered reduced } \\
\text { graphene oxide }\end{array}$ & $20 \Omega$ & $25 \Omega$ after 10 cycles & - & - & $\begin{array}{l}1000 \mathrm{~h} \text { at } 1 \mathrm{~mA} \mathrm{~cm}^{-2} \\
1 \mathrm{~mA} \mathrm{~h} \mathrm{~cm}^{-2}\end{array}$ \\
\hline \multirow[t]{5}{*}{$\begin{array}{l}\text { Lithiophilic coatings on the } \\
\text { host material }\end{array}$} & {$[50]$} & Coating lithiophilic Si & $\sim 60 \Omega$ & $\sim 40 \Omega$ after 1 cycle & - & - & $\begin{array}{l}80 \text { cycles under a high } \\
\text { current rate of } 3 \mathrm{~mA} \mathrm{~cm}^{-2} \text {, } \\
1 \mathrm{~mA} \mathrm{~h} \mathrm{~cm}^{-2}\end{array}$ \\
\hline & [51] & $\mathrm{ZnO}$-coated carbon matrix & $60 \Omega$ & $40 \Omega$ after 3 cycles & $\begin{array}{l}20 \mathrm{mV} \text { at } 0.5 \mathrm{~mA} \cdot \mathrm{cm}^{-2}, \\
1 \mathrm{~mA} \mathrm{~h} \cdot \mathrm{cm}^{-2}\end{array}$ & $\begin{array}{l}65 \mathrm{mV} \text { at } 0.5 \mathrm{~mA} \cdot \mathrm{cm}^{-2}, \\
1 \mathrm{~mA} \mathrm{~h} \cdot \mathrm{cm}^{-2}\end{array}$ & $\begin{array}{l}\text { Over } 200 \mathrm{~h} \text { at } 0.5 \mathrm{~mA} \cdot \mathrm{cm}^{-2}, \\
1 \mathrm{~mA} \mathrm{~h} \cdot \mathrm{cm}^{-2}\end{array}$ \\
\hline & [52] & $\begin{array}{l}\text { ZnO coated polyimide (PI) } \\
\text { matrix }\end{array}$ & - & - & $\begin{array}{l}35 \mathrm{mV} \text { at } 1 \mathrm{~mA} \mathrm{~cm}^{-2} \\
1 \mathrm{~mA} \mathrm{~h} \mathrm{~cm}^{-2}\end{array}$ & $\begin{array}{l}40 \mathrm{mV} \text { after } 100 \text { cycles at } \\
1 \mathrm{~mA} \mathrm{~cm}^{-2}, 1 \mathrm{~mA} \mathrm{~h} \mathrm{~cm}^{-2}\end{array}$ & $\begin{array}{l}100 \text { cycles at } 1 \mathrm{~mA} \mathrm{~cm}^{-2} \\
1 \mathrm{~mA} \mathrm{~h} \mathrm{~cm}^{-2}\end{array}$ \\
\hline & [55] & $\begin{array}{l}\text { Electroplated } \mathrm{Ag} \text { on the } \\
\text { carbon fiber (CF) framework }\end{array}$ & - & - & - & $\sim 60 \mathrm{mV}$ after 200 cycles & $400 \mathrm{~h}$ at $1 \mathrm{~mA} \mathrm{~cm}$ \\
\hline & [56] & $\begin{array}{l}\text { Graphitic carbon nitrite layer } \\
\text { coated carbon cloth }\end{array}$ & $\sim 60 \Omega$ & $\sim 30 \Omega$ after 100 cycles & - & $\begin{array}{l}\sim 80 \mathrm{mV} \text { over } 1500 \mathrm{~h} \text { at } \\
2.0 \mathrm{~mA} \mathrm{~cm}^{-2}, 1 \mathrm{~mA} \mathrm{~h} \mathrm{~cm}^{-2}\end{array}$ & 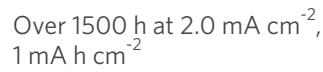 \\
\hline \multirow[t]{2}{*}{$\begin{array}{l}\text { Lithiophilic dopants on the } \\
\text { host materials }\end{array}$} & [57] & $\begin{array}{l}\text { CuBr-and Br-doping } \mathrm{Cu} \\
\text { Current Collectors }\end{array}$ & $\sim 24 \Omega$ & $12.7 \Omega$ after 60 cycles & $\begin{array}{l}\text { Less than } 25 \mathrm{mV} \text { over } 800 \mathrm{~h} \text { at } \\
1 \mathrm{~mA} \mathrm{~cm}^{-2}, 1 \mathrm{~mA} \mathrm{~h} \mathrm{~cm}\end{array}$ & $\begin{array}{l}98.8 \% \text { over } 300 \text { cycles at } \\
2.0 \mathrm{~mA} \mathrm{~cm}^{-2}, 2.0 \mathrm{~mA} \mathrm{~h} \mathrm{~cm}^{-2}\end{array}$ & $\begin{array}{l}850 \mathrm{~h} \text { at } 2.0 \mathrm{~mA} \mathrm{~cm}^{-2} \\
2.0 \mathrm{~mA} \mathrm{~h} \mathrm{~cm}^{-2}\end{array}$ \\
\hline & [58] & $\mathrm{N}$-doped graphene & - & - & - & $\begin{array}{l}98 \% \text { near } 200 \text { cycles at } \\
1.0 \mathrm{~mA} \mathrm{~cm}^{-2}, 1.0 \mathrm{~mA} \mathrm{~h} \mathrm{~cm}^{-2}\end{array}$ & $\begin{array}{l}\text { Over } 140 \mathrm{cycles}^{-2} \text { at } \\
2.0 \mathrm{~mA} \mathrm{~cm}{ }^{-2} \\
0.042 \mathrm{~mA} \mathrm{hm}^{-2}\end{array}$ \\
\hline \multirow[t]{3}{*}{ Alloying anode materials } & [61] & Li-Al alloy & - & - & - & $\begin{array}{l}98.6 \% \text { for } 85 \text { cycles at } \\
0.5 \mathrm{~mA} \mathrm{~cm}^{-2}, 2 \mathrm{~mA} \mathrm{~h} \mathrm{~cm}^{-2}\end{array}$ & $\begin{array}{l}1700 \mathrm{~h} \text { at } 0.5 \mathrm{~mA} \mathrm{~cm}^{-2}, \\
1 \mathrm{~mA} \mathrm{~h} \mathrm{~cm}^{-2}\end{array}$ \\
\hline & {$[62]$} & Mg doped Li-LiB alloy & - & $\begin{array}{l}15 \Omega \text { after the first } \\
\text { cycle }\end{array}$ & $\begin{array}{l}\text { Less than } 50 \mathrm{mV}^{-2} \text { after } 500 \mathrm{~h} \\
\text { at } 0.5 \mathrm{~mA} \mathrm{~cm}^{-2}, 0.5 \mathrm{~mA} \mathrm{hm}^{-2}\end{array}$ & - & $\begin{array}{l}500 \mathrm{~h} \text { at } 0.5 \mathrm{~mA} \mathrm{~cm}^{-2} \\
0.5 \mathrm{~mA} \mathrm{~h} \mathrm{~cm}^{-2}\end{array}$ \\
\hline & [63] & GalnSnZn liquid metal & - & - & $\begin{array}{l}\text { Less } 0.15 \mathrm{~V} \text { after } 300 \mathrm{~h} \text { at } \\
1.0 \mathrm{~mA} \mathrm{~cm}^{-2}, 0.5 \mathrm{~mA} \mathrm{~h} \mathrm{~cm}^{-2}\end{array}$ & - & $\begin{array}{l}400 \mathrm{~h} \text { at } 1.0 \mathrm{~mA} \mathrm{~cm} \\
0.5 \mathrm{~mA} \mathrm{~h}^{-2}\end{array}$ \\
\hline
\end{tabular}

As discussed above, the factors affecting lithiophilicity include surface energy and chemical interactions. Following these principles, the surface energy can be tuned by increasing the temperature and effective surface modifications. Li melts into a molten state above $180.5^{\circ} \mathrm{C}$. This temperature increase is beneficial for improving the lithiophilicity due to the entropy increase, viscosity decrease and surface tension decline of molten $\mathrm{Li}^{\left[{ }^{[17]}\right.}$. The addition of alloying additives (like $\mathrm{Sn}$, In and $\mathrm{Mg}$ ) and organic coatings (such as $-\mathrm{COOH},-\mathrm{OH}$ and $-\mathrm{F}$ ) into molten Li can also significantly improve the lithiophilicity via reducing the surface energy and Gibbs formation energy ${ }^{[4]}$. Li-reactive coatings on solid electrolytes, such as $\mathrm{Au}, \mathrm{Al}$ or $\mathrm{Al}_{2} \mathrm{O}_{3}$ interlayers, can enhance the lithiophilicity between $\mathrm{Li}$ and solid electrolytes via chemical interactions with $\mathrm{Li}^{[17]}$. To date, various strategies have been proposed to ameliorate the lithiophilicity of solid electrolytes. These strategies are mainly focused on physical contact improvement, surface energy adjustment and chemical interaction exploration. With improved 
Table 3. Summary of the improvement of lithiophilicity of solid electrolytes

\begin{tabular}{|c|c|c|c|c|c|c|c|}
\hline \multicolumn{8}{|c|}{ Lithiophilicity of solid electrolytes } \\
\hline Strategy & Ref. & Method & $\begin{array}{l}\text { Interfacial resistance } \\
\text { (before cycling) }\end{array}$ & $\begin{array}{l}\text { Interfacial resistance } \\
\text { (after cycling) }\end{array}$ & $\begin{array}{l}\text { Polarized potential } \\
\text { (after cycling) }\end{array}$ & Li-Cu efficiency & Cycling life \\
\hline \multirow[t]{8}{*}{$\begin{array}{l}\text { Improving } \\
\text { physical contact }\end{array}$} & [64] & $\begin{array}{l}\text { IL interlayer (N-propyl-N-methylpyrrolidiniumbis } \\
\text { (trifluoromethanesulfonyl) amide) }\end{array}$ & $6000 \Omega$ & $320 \Omega$ & $\begin{array}{l}40 \mathrm{mV} \text { at } 0.1 \mathrm{~mA} \mathrm{~cm}{ }^{-2} \\
0.2 \mathrm{~mA} \mathrm{~h} \mathrm{~cm}\end{array}$ & - & $\begin{array}{l}100 \text { cycles at } 0.5 \mathrm{C} \text { for } \\
\text { Li|LFP }\end{array}$ \\
\hline & [65] & $\begin{array}{l}\text { IL interlayer (1-ethyl-3-methylimidazolium }{ }_{0.8} \mathrm{Li}_{0.2} \text { ) } \\
\text { (TFSI) }\end{array}$ & - & - & $\begin{array}{l}70 \mathrm{mV} \text { at } 0.2 \mathrm{~mA} \mathrm{~cm}^{-2} \\
0.2 \mathrm{~mA} \mathrm{~h} \mathrm{~cm}\end{array}$ & - & $\begin{array}{l}100 \text { cycles at } 0.1 \mathrm{C} \text { for } \\
\text { Li|LFP }\end{array}$ \\
\hline & {$[66]$} & IL interlayer (BMP)-TFSI & - & - & $\begin{array}{l}17 \mathrm{mV} \text { at } 0.1 \mathrm{~mA} \mathrm{~cm} \\
0.1 \mathrm{~mA} \mathrm{~h} \mathrm{~cm}\end{array}$ & - & $\begin{array}{l}200 \text { cycles at } 0.5 \mathrm{C} \text { for } \\
\text { Li|NCM } 811\end{array}$ \\
\hline & [67] & Gel interlayer containing Al-(oxy)fluorides & - & - & $\begin{array}{l}345 \mathrm{mV} \text { at } 4 \mathrm{~mA} \mathrm{~cm} \\
2 \mathrm{~mA} \mathrm{~h} \mathrm{~cm}^{-2}\end{array}$ & - & $\begin{array}{l}200 \text { cycles at } 1 \mathrm{C} \text { for } \\
\text { Li|LFP }\end{array}$ \\
\hline & [68] & Gel interlayer (LiTFSI-LiPF 6 ) & - & - & - & - & $\begin{array}{l}300 \text { cycles at } 0.5 \mathrm{C} \text { for } \\
\text { Li|LFP }\end{array}$ \\
\hline & [69] & Gel interlayer with $\mathrm{LiNO}_{3}$ & - & - & - & 97\% after 100 cycles & $\begin{array}{l}100 \text { cycles at } 0.1 \mathrm{C} \text { for } \\
\text { Li|LFP }\end{array}$ \\
\hline & {$[70]$} & $\begin{array}{l}\text { Polymer interlayer poly(ethylene glycol) methyl } \\
\text { ether acrylate }\end{array}$ & - & - & - & $\begin{array}{l}99.8 \%-100 \% \text { over } 640 \\
\text { cycles for Li|LFP }\end{array}$ & $\begin{array}{l}640 \text { cycles at } 0.6 \mathrm{C} \text { for } \\
\text { Li|LFP }\end{array}$ \\
\hline & 71 & Polymer interlayer PEGDA & - & - & $\begin{array}{l}40 \mathrm{mV} \text { at } 2 \mathrm{~mA} \mathrm{~cm}^{-2} \\
2 \mathrm{~mA} \mathrm{~h} \mathrm{~cm}\end{array}$ & $\begin{array}{l}99.8 \% \text { after } 270 \text { cycles } \\
\text { for Li|NCM622 }\end{array}$ & $\begin{array}{l}270 \text { cycles at } 0.5 \mathrm{C} \text { for } \\
\text { Li|NCM622 }\end{array}$ \\
\hline Chemical & [76] & Li-Sn anode & - & $7 \Omega \mathrm{cm}^{2}$ & - & - & - \\
\hline \multirow[t]{7}{*}{ interaction } & [77] & Li-C anode & $381 \Omega \mathrm{cm}^{2}$ & $11 \Omega \mathrm{cm}^{2}$ & - & - & - \\
\hline & {$[20]$} & Li-Mg anode & $1000 \Omega \mathrm{cm}^{2}$ & $70 \Omega \mathrm{cm}^{2}$ & - & - & - \\
\hline & [23] & Li-Al anode & - & $75 \Omega \mathrm{cm}^{2}$ & - & - & - \\
\hline & [22] & Li-Zn anode & $2000 \Omega \mathrm{cm}^{2}$ & $20 \Omega \mathrm{cm}^{2}$ & - & - & - \\
\hline & {$[81]$} & $\mathrm{Mg}_{3} \mathrm{~N}_{2}$ interlayer & - & - & - & - & $\begin{array}{l}200 \text { cycles at } 0.5 \mathrm{C} \text { for } \\
\text { Li|LFP }\end{array}$ \\
\hline & [83] & Graphite interlayer & $1078 \Omega \mathrm{cm}^{2}$ & $58 \Omega \mathrm{cm}^{2}$ & - & - & $\begin{array}{l}100 \text { cycles at } \\
0.1 \mathrm{~mA} \mathrm{~cm}^{-2} \text { for } \\
\text { Li|NCM111 }\end{array}$ \\
\hline & [86] & HFE interlayer & $127.4 \Omega \mathrm{cm}^{-2}$ & $48.4 \Omega \mathrm{cm}^{-2}$ & $\begin{array}{l}90 \mathrm{mV} \text { at } 0.5 \mathrm{~mA} \mathrm{~cm}^{-2} \text {, } \\
0.1 \mathrm{~mA} \mathrm{hm}^{-2}\end{array}$ & - & $\begin{array}{l}100 \text { cycles at } \\
0.1 \mathrm{~mA} \mathrm{~cm}^{-2} \text { for Li|LCO }\end{array}$ \\
\hline
\end{tabular}

lithiophilicity, interfacial problems like poor contact and huge interfacial impedance can be addressed, thereby furthering the application of advanced solidstate Li-metal batteries. 


\section{Improving physical contact}

The introduction of liquid interlayers enables improved physical contact between solid-solid interfaces. Among the various liquid electrolytes species, ionic liquid (IL) electrolytes show advantages in terms of safety and good compatibility with Li metal anodes. Using an IL, N-propyl-Nmethylpyrrolidiniumbis(trifluoromethanesulfonyl) amide, mixed with LiTFSI as an interlayer, Ma et al. ${ }^{[63]}$ proposed an electrolyte design with cellulose acetate/polyethylene glycol/ $\mathrm{Li}_{1.4} \mathrm{Al}_{0.4} \mathrm{Ti}_{1.6} \mathrm{P}_{3} \mathrm{O}_{12}$ [Figure $\left.4 \mathrm{~A}\right]$ that exhibited a high $\mathrm{Li}^{+}$transference number of 0.61 and reduced interfacial resistance from 6000 to $320 \Omega$. Taking advantage of its high viscosity and poor flammability, the IL interlayer showed satisfactory viscoelasticity and excellent safety, as well as facilitating the uniform deposition of metallic Li. Furthermore, Wang et al. ${ }^{[64]}$ demonstrated a metal-organic framework-based electrolyte impregnated with an IL [1-ethyl3-methylimidazolium ${ }_{0.8} \mathrm{Li}_{0.2}$-bis(trifluoromethylsulfonyl)amide]. Featuring a nano-wetting interfacial mechanism, the electrolyte exhibited excellent compatibility with a Li metal anode and led to a small polarization voltage of $\pm 70 \mathrm{mV}$ in Li|Li symmetric cells under $0.2 \mathrm{~mA} \mathrm{~cm}^{-2}$. Similarly, Zhang et al. ${ }^{[65]}$ introduced a 1-butyl-1-methylpyrrolidinium (BMP)-TFSI interlayer on the surface of a garnet electrolyte and the obtained hybrid electrolyte showed an ultrahigh $\mathrm{Li}^{+}$transference number of 0.99 and a critical current density larger than $0.74 \mathrm{~mA} \mathrm{~cm}^{-2}$. Benefiting from its good lithiophilicity, the obtained electrolyte enabled continuous ionic transport at the interface and allowed for a stable voltage polarization of $0.17 \mathrm{~V}$ for more than 300 cycles in Li|Li symmetric cells.

The introduction of gel interlayers to construct intimate soft solid-solid contacts is another method to improve the physical contact between two solid interfaces. The construction of in-situ interlayers represents an alternative used to tighten contact and reduce interfacial resistance. For example, via an in-situ electrochemical lithiation reaction, nanosized $\mathrm{AlPO}_{4}$ particles dispersed in the quasi-solid electrolyte can turn into repellent containing $\mathrm{Al}$-(oxy)fluorides, which have been proved to stabilize the electrode interface. With the repellent transitional interlayer as a $\mathrm{Li}$ anode safeguard, the constructed $\mathrm{Li}-\mathrm{LiFePO}_{4}$ batteries can maintain a capacity retention of over $85 \%$ for 200 cycles at $55{ }^{\circ} \mathrm{C}$ without Li dendrites detected ${ }^{[66]}$. A dualsalt (LiTFSI-LiPF ${ }_{6}$ ) gel polymer electrolyte with a robust SEI interlayer was constructed through the in-situ polymerization of poly(ethylene glycol) diacrylate (PEGDA) and ethoxylated trimethylolpropane triacrylate. In the formation of the SEI for the Li metal anode, COR and COOR could be detected in the gel electrolyte and after cycling, the $\mathrm{COR}$ and $\mathrm{COOR}$ signals were still strong. $\mathrm{CO}_{3}^{2-}$ and $\mathrm{CF}_{3}$ signals were not detected, indicating a lack of decomposition of the solvent and salts. Therefore, the SEI in the gel system was sufficiently stable and robust to inhibit the growth of Li dendrites, allowing for a capacity retention of 87.93\% after 300 cycles in $\mathrm{LiFePO}_{4} \mid$ gel|Li cells ${ }^{[67]}$. A double polymer network gel electrolyte design with $\mathrm{LiNO}_{3}$ additives also offers a method to steady the interface via the in-situ formation of a stable SEI layer containing ROLi, ROCOOLi and $\mathrm{LiN}_{\mathrm{x}} \mathrm{O}_{\mathrm{y}}$ species. $\mathrm{LiNO}_{3}$ can react with electrolytes and form a robust SEI, which enables symmetric cells to cycle for $400 \mathrm{~h}$ with a dendrite-free morphology ${ }^{[68]}$.

Soft solid-solid contact can also be achieved through the introduction of polymer electrolyte interlayers. The group of Goodenough proposed a polymer/ceramic/polymer sandwich structure, in which the crosslinked poly(ethylene glycol) methyl ether acrylate polymer interlayer wets well with the Li metal anode and triggers a homogenous $\mathrm{Li}^{+}$flux at the interface. Therefore, Li dendrites were significantly inhibited and full cells with $\mathrm{LiFePO}_{4}$ electrodes exhibited a high CE of $99.8 \%-100 \%$ over 640 cycles $^{[69]}$. Additionally, a heterogeneous multilayered solid electrolyte was proposed, in which PEGDA adheres to the Li anode while PAN faces the cathode and PAN@Li $\mathrm{Li}_{1.4} \mathrm{Al}_{0.4} \mathrm{Ge}_{1.6}\left(\mathrm{PO}_{4}\right)_{3}$ (LAGP) functions as an electrolyte interlayer in the middle [Figure $4 \mathrm{~B}]^{[70]}$. The introduced PEGDA has good compatibility with Li metal and stands as a soft interlayer to avoid direct contact between LAGP and the Li metal anode, which enables the construction of Li|Li symmetric cells with a stable polarization of less than $40 \mathrm{mV}$ for more than $1000 \mathrm{~h}$ at $2 \mathrm{~mA} \mathrm{~cm} \mathrm{~cm}^{-2}$. The multilayer structure exhibits good compatibility at both the cathode and anode sides, thereby broadening 
A

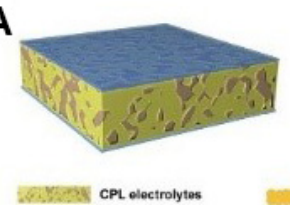

WaXsises CPL electrolytas
Viscoelastic intertace

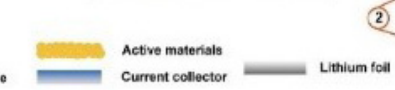

B

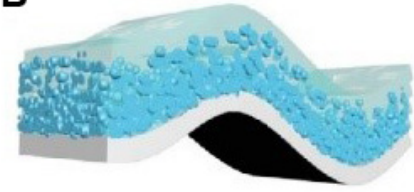

PAN LAGP PEGDA

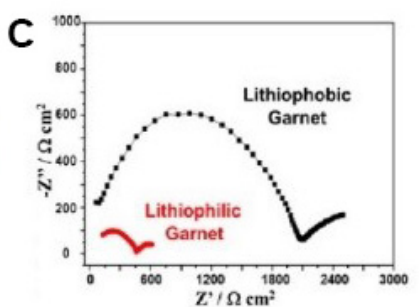

Good Li wetting

D Poor Li wetting
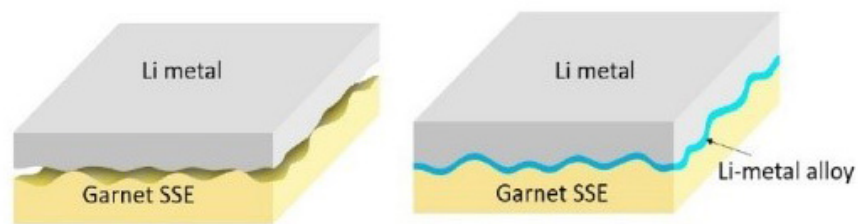
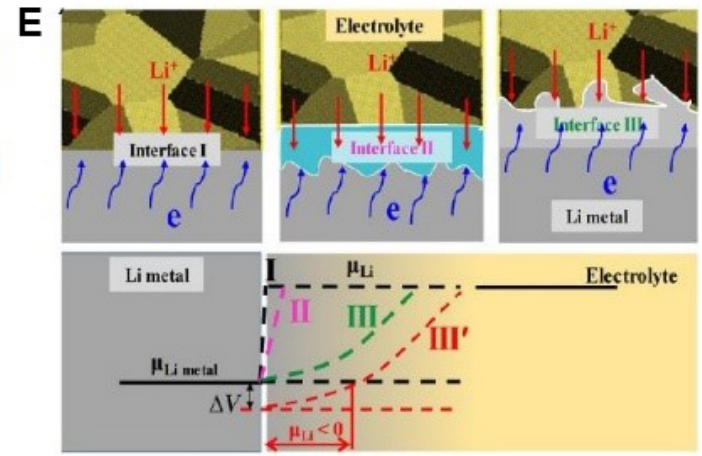

$\mathbf{F}$

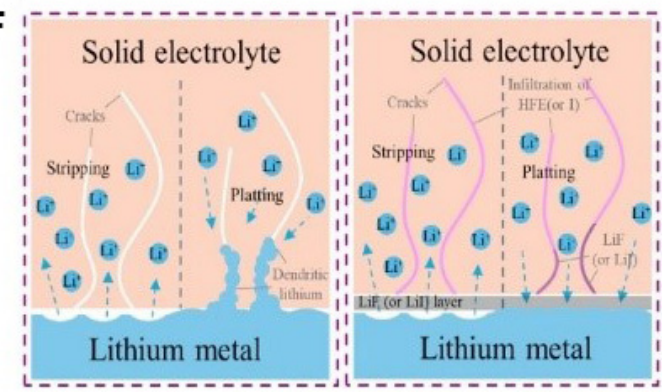

Figure 4. (A) Schematic of electrolyte design with viscoelastic ionic liquid (IL) as interlayers. In Li-metal batteries, the IL interlayers can buffer the interfacial contact and their viscoelasticity can efficiently facilitate the homogeneous deposition of $\mathrm{Li}$ ions ${ }^{[63]}$. Copyright 2019, Wiley-VCH. (B) Schematic of a heterogeneous multilayered solid electrolyte. When the electrolyte is applied in Li-metal batteries, polyethylene glycol diacrylate (PEGDA) is on the Li anode side and poly (acrylonitrile) (PAN) faces the cathode side. The middle layer is the electrolyte $\mathrm{Li}_{1.4} \mathrm{Al}_{0.4} \mathrm{Ge}_{1.6}\left(\mathrm{PO}_{4}\right)_{3}(\mathrm{LAGP})$ mixed with $\mathrm{PAN}{ }^{[71]}$. Copyright 2019, Wiley- $\mathrm{VCH}$. (C) The Li-alloy interlayer can turn the surface from lithiophobic to lithiophilic. From the electrochemical impedance spectroscopy (EIS) measurements, the interfacial resistance of symmetric cells with lithiophilic garnet is much lower than that of lithiophobic garnet ${ }^{[78]}$. Copyright 2016, American Chemical Society. (D) Comparison of interfaces with and without Li-metal alloy interlayer. The pristine garnet electrolyte exhibits poor wetting behaviors with Li. After coating a metal interlayer, a Li metal alloy will form at the interface and improve the contact, therefore improving the lithiophilicity and decreasing the interfacial resistance ${ }^{[23]}$. Copyright 2017, American Association for the Advancement of Science. (E) Classifications of interfaces between Li metal and solid electrolyte along with the changes of Li potentials at different interfaces. Interface I indicates the thermodynamically stable interface. Interface II refers to the electronic isolating interface and interface III refers to the electronic conducting interface. The Li potential drops abruptly from the electrolyte to Li metal in interface II, which can effectively block side reactions ${ }^{[84]}$. Copyright 2018, American Association for the Advancement of Science. (F) Comparison of Li stripping/plating behaviors in pristine solid electrolyte and methoxyperfluorobutane (HFE) treated electrolyte. Li dendrites can easily form in the pristine solid electrolyte. The introduced HFE can react with Li and form a LiF interlayer, which can efficiently inhibit dendrite growth. If the Li dendrites break the interlayer, the HFE in electrolytes can still consume the Li and repair the interlayer ${ }^{[85]}$. Copyright 2018, Elsevier.

the electrochemical window to $5 \mathrm{~V}$ and allowing the application of high-voltage cathodes like $\mathrm{LiNi}_{0.6} \mathrm{Co}_{0.2} \mathrm{Mn}_{0.2} \mathrm{O}_{2}(\mathrm{NCM} 622)$ and $\mathrm{LiNi}_{0.8} \mathrm{Co}_{0.1} \mathrm{Mn}_{0.1} \mathrm{O}_{2}$ (NCM811), which are rarely used in solid-state Limetal batteries ${ }^{[71]}$. Inspired by this design, many other strategies using polymer interlayers have also been reported, such as asymmetric solid electrolytes ${ }^{[72]}$, Janus structures ${ }^{[73]}$ and thio-LiSICON/polymer composite electrolytes $^{[74]}$.

IL and gel interlayers can improve the lithiophicility of solid electrolytes; however, the leakage of liquid components from the electrolyte|Li interface leads to safety concerns. Increasing the polymer ratio of the interlayer can decrease leakage risks, while the poor ionic conductivity of polymers harms the workability of batteries at ambient temperatures. The exploration of high-conductivity and lean-electrolyte systems could shed light on building interlayers with better safety. 


\section{Surface energy and chemical interactions}

Additives can effectively manipulate the surface energy of molten Li and therefore improve the lithiophilicity on different substrates. The group of $\mathrm{Hu}$ added alloying elements (like $\mathrm{Sn}, \mathrm{Zn}$ and $\mathrm{Si}$ ) into molten $\mathrm{Li}$ and the Li alloys exhibited outstanding lithiophilicity against various substrates. The Li alloys contacted tightly with garnet electrolytes and the interfacial resistance of Li-Sn alloy symmetric cells was decreased to only $7 \Omega \mathrm{cm}^{2}$, demonstrating remarkable electrochemical stability ${ }^{[75]}$. Using graphite as an additive, a paste-like Li-C composite anode was obtained, which exhibits excellent lithiophilicity against garnet electrolytes and reduced interfacial resistance from 381 to $11 \Omega \mathrm{cm}^{2[76]}$.

Inorganic solid electrolytes show promise in high-safety Li-metal batteries due to their desirable mechanical strength and poor flammability. Among the various inorganic solid electrolytes, garnet-type solid electrolytes show considerable potential in applications, owing to their excellent chemical/electrochemical stability and relatively high ionic conductivity. However, due to their poor lithiophilicity with Li-metal anodes, garnet-type solid electrolytes exhibit high interfacial resistance and low critical current density, leading to the possible formation and penetration of $\mathrm{Li}$ dendrites. $\mathrm{Li}_{6.4} \mathrm{La}_{3} \mathrm{Zr}_{1.4} \mathrm{Ta}_{0.6} \mathrm{O}_{12}$ (LLZT) is a representative garnet-type electrolyte. Impurities, like $\mathrm{Li}_{2} \mathrm{O}$ and $\mathrm{Li}_{2} \mathrm{CO}_{3}$, are very easy to generate at the interface between LLZT and Li metal, causing poor lithiophilicity and high interfacial resistance. $\mathrm{Li}_{2} \mathrm{O}$ has a positive formation energy $\left(0.23 \mathrm{~J} \mathrm{~cm}^{-2}\right)$ and therefore LLZT covered by $\mathrm{Li}_{2} \mathrm{O}$ cannot wet well with $\mathrm{Li}$. By rubbing LLZT pellets into molten $\mathrm{Li}$, the superficial impurities are polished and the exposed LLZT becomes sufficiently wetted by $\mathrm{Li}$, which is consistent with the negative Li/LLZT formation energy $\left(-6.14 \mathrm{~J} \mathrm{~cm}^{-2}\right)$. Benefiting from the intrinsic lithiophilicity, the interfacial impedance of $\mathrm{Li} \mid \mathrm{Li}$ symmetric cells decreased to $6.95 \Omega \mathrm{cm}^{2}$, accompanied by an increased critical current density of $13.3 \mathrm{~mA} \mathrm{~cm}{ }^{-2}$ and a stable cycling performance over $950 \mathrm{~h}$ at room temperature ${ }^{[77]}$.

To improve the wettability, the polishing strategy is only applicable to planar surfaces other than geometric surfaces and is not scalable based on current technology. Therefore, various interfacial engineering methods have been explored, mainly focusing on high electronic conducting, mixed ionic-electronic conducting and ionic conducting but electronic insulating interlayers. Recently, coating metals, such as $\mathrm{Si}^{[78]}, \mathrm{Mg}^{[20]}, \mathrm{Al}^{[23,79]}$ and $\mathrm{Ge}^{[19]}$, or metal oxides, like $\mathrm{Al}_{2} \mathrm{O}_{3}{ }^{[19]}$ and $\mathrm{ZnO}^{[22]}$, can trigger an alloying reaction with $\mathrm{Li}$ and form high electronic conducting Li-metal alloy interlayers. Li-metal alloy interlayers exhibit excellent lithiophilicity with $\mathrm{Li}$ and significantly improve the physical contact, leading to an even current distribution and low interfacial resistance [Figure $4 \mathrm{C}$ ]. Taking $\mathrm{Mg}$ as an example, the $\mathrm{Mg}$ atoms diffuse into the Li metal anode during the alloying process and then form as a transient layer, leading to enhanced solid-solid contact that significantly decreases the interfacial resistance from 1000 to $70 \Omega \mathrm{cm}^{2[20]}$. Similarly, the formation of a Li-Al alloy transforms the garnet surface from lithiophobic to lithophilic with a decreased interfacial resistance of $75 \Omega \mathrm{cm}^{2}$ [Figure $\left.4 \mathrm{D}\right]^{[23]}$. When a metal oxide interlayer, like $\mathrm{ZnO}$, is introduced via atomic layer deposition, $\mathrm{Li}$ atoms tend to diffuse into the interlayer and reduce $\mathrm{ZnO}$ into a $\mathrm{Li}-\mathrm{Zn}$ alloy, which effectively tightens the contact and reduces the interfacial resistance from 2000 to $20 \Omega \mathrm{cm}^{2[22]}$.

Modulating the surface energy via Li alloying additives can improve the lithiophilicity of solid electrolytes, which offers a promising solution from a chemical perspective. However, these strategies still face problems in all battery systems and long cycling situations, owing to the consumption of additives and deterioration of the chemical environment. The stability of alloyed interfaces at operating conditions is reliant on future research.

In terms of improving lithiophilicity, high electronic conducting interlayers can significantly boost physical contact and reduce interfacial resistance, contributing to decreased overpotentials during cycling. However, 
with enhanced ionic conductivity, mixed ionic-electronic conducting interlayers, like $\mathrm{Mg}_{3} \mathrm{~N}_{2}^{[80]}, \mathrm{Li}_{3} \mathrm{PO}_{4}{ }^{[81]}$ and graphite ${ }^{[82]}$, present remarkable potential for inhibiting Li dendrites. Via an in-situ reaction with the Li metal anode, the introduced $\mathrm{Mg}_{3} \mathrm{~N}_{2}$ layer transforms into electronic conducting $\mathrm{Mg}$ and ionic conducting $\mathrm{Li}_{3} \mathrm{~N}$, with $\mathrm{Mg}$ leading to an even current distribution and $\mathrm{Li}_{3} \mathrm{~N}$ contributing to a homogeneous concentration gradient of $\mathrm{Li}^{+}$, therefore prohibiting the formation and growth of $\mathrm{Li}$ dendrites ${ }^{[80]}$. In addition, the group of Maruga reported that, as well as reducing the interfacial resistance from 1078 to $58 \Omega \mathrm{cm}^{2}, \mathrm{Li} \mid \mathrm{Li}$ symmetric cells with graphite as a mixed ionic-electronic conducting interlayer could also afford a high critical current density $(750 \mu \mathrm{A} \mathrm{cm})^{-2}$.

Although high electronic conducting interlayers can improve contact and mixed ionic-electronic conducting interlayers exhibit the ability to prohibit Li dendrites, their electronic conducting properties make it difficult for them to block side reactions. As shown in Figure 4E, interface I represents a thermodynamically stable contact between the electrolyte and Li metal anode, which is unrealistic. Interface III refers to high electronic or mixed ionic-electronic conducting interlayers, which can conduct electrons. The potential in interface III gradually changes from the electrolyte to the Li anode and therefore continuous side reactions cannot be easily avoided in the above two interlayers. The ionic conducting but electronic isolating interlayers are classified as interface II, in which Li ions can easily transport. The electronic isolating properties of interface II lead to an abrupt potential drop from the electrolyte to Li metal, which can efficiently prohibit parasitic reactions.

Therefore, various kinds of electronic insulating interlayers, including $\mathrm{LiF}^{[83-85]}, \mathrm{Li}_{3} \mathrm{~N}^{[86]}$ and $\mathrm{Li}_{3} \mathrm{OCl}^{[87]}$, have attracted significant interest, among which LiF is mostly researched. LiF possesses the properties of a low surface diffusion barrier and high interfacial energy, which makes the Li ions wet the interface planarly instead of forming needle-like dendrites ${ }^{[83]}$. A robust LiF-rich interlayer can be formed via an in-situ reaction between the LiFSI-coated solid electrolyte $\mathrm{Li}_{3} \mathrm{PS}_{4}$ and the Li metal anode, which can effectively block side reactions and inhibit Li dendrites, thereby contributing to an increased critical current density of more than $2 \mathrm{~mA} \mathrm{~cm}^{-2}$ and an enhanced CE of $98 \%{ }^{[84]}$. Similarly, the added HFE in the solid electrolyte $\mathrm{Li}_{7} \mathrm{P}_{3} \mathrm{~S}_{11}$ can react with the $\mathrm{Li}$ metal anode and produce a $\mathrm{LiF}$ interlayer, which can protect the electrolyte from penetrating dendrites. If the dendrites pierce the LiF interlayer, the HFE in the electrolyte immediately reacts with the $\mathrm{Li}$ in dendrites and forms new $\mathrm{LiF}$ to repair the broken interface, therefore ensuring a steady interface structure and stable cycling over 200 cycles in $\mathrm{Li} \mid \mathrm{Li}$ symmetric cells [Figure $4 \mathrm{~F}$ ] ${ }^{[85}$. Therefore, interface II with poor electronic conductivity shows a better ability to inhibit side reactions compared to interface III. Constructing an electronic isolating interface instead of a mixed ionic-electronic conducting interlayer might be a reasonable method to address interfacial problems and boost lithiophilicity.

\section{CONCLUSION AND OUTLOOK}

A lithiophilic electrode/electrolyte interface is vital for the stable operation of rechargeable Li-metal batteries. Due to the different physiochemical properties of liquid and solid electrolytes, the cases of lithiophilicity vary significantly in liquid and solid-state batteries. In this review, we have summarized the challenges and strategies for improving the interfacial lithiophilicity in different types of rechargeable Limetal batteries.

For liquid electrolyte-based batteries, the precise manipulation of the structure and chemical compositions of the SEI on the Li metal surface is required to enable improved wetting and (electro)chemical stability at the anode/electrolyte interface. A smooth anode surface via chemical treatment (e.g., polishing) is favorable for homogenizing the ion distribution at the anode surface and contributes to dendrite-free plating/stripping. Host materials with suitable porous structures have received attention as they can 
suppress dendrite evolution and lithium volume change, and various strategies, including elemental additives, surface coatings, dopants and alloying materials, were proposed to improve the lithiophilicity of host materials via reducing the surface and Gibbs formation energies.

Solid electrolytes usually show poor lithiophilicity and high interfacial resistance vs. the Li metal anode, which account for the rapid performance degradation of the battery. To address these issues, one approach is to improve the contact at the Li/electrolyte interface. In-situ formed polymers can improve the interfacial contact due to their high flexibility against the anode surface. In the case where the interlayer consists of electronically conductive materials, such as metals or metal oxides, the alloying/conversion reaction with $\mathrm{Li}$ that occurs at the interface acts as the driving force for wetting and contributes to improved interfacial $\mathrm{Li}^{+}$ mobility. A mixed ionic-electronic conductive interlayer is able to trigger homogeneous distribution of $\mathrm{Li}$ ions and therefore effectively inhibit the growth of dendrites. In contrast, an ionically conductive but electronically isolative interlayer (e.g., LiF) is applied to suppress parasitic reactions as it brings an abrupt potential drop at the interface. An interlayer with multiple sublayers or a composite design would be desired to achieve optimal storage performance.

It is noteworthy that, despite the progress made so far in improving the interfacial contact of electrolytes against Li metal, there are still many challenges toward the realization of high-energy Li-metal batteries, including:

1. Although the initial state of interfacial lithiophilicity can be improved, it remains difficult to maintain contact upon the hostless evolution of interface/volume at the anode side during the repeated cycling process.

2. The dynamic evolution of morphology, structure, chemical compositions and their physiochemical properties at the anode/electrolyte interface requires further investigation.

3. A deep understanding of the interfacial lithiophilicity within a wide temperature range is required for the safe operation of batteries.

4. Advanced characterization tools and theoretical calculations are required to resolve the interfacial wetting behavior and the science behind it.

\section{DECLARATIONS}

\section{Authors' contributions}

Preparing the manuscript draft: Li CC, Zhang XS, Zhu YH

Writing - review and editing, funding acquisition, supervision: Zhang Y, Xin S, Wan LJ, Guo YG

\section{Availability of data and materials}

Not applicable.

\section{Financial support and sponsorship}

This work was supported by the National Key R\&D Program of China (Grant No. 2019YFA0705700), the Basic Science Center Project of National Natural Science Foundation (Grant No. 51788104), the National Natural Science Foundation of China (Grant Nos. 21975266 and 22005316). Xin S acknowledges financial support from the start-up funds from the Chinese Academy of Sciences. 


\section{Conflicts of interest}

All authors declared that there are no conflicts of interest.

\section{Ethical approval and consent to participate}

Not applicable.

\section{Consent for publication}

Not applicable.

\section{Copyright}

(C) The Author(s) 2021.

\section{REFERENCES}

1. Zheng J, Ji G, Fan X, et al. High-fluorinated electrolytes for Li-S batteries. Adv Energy Mater 2019;9:1803774. DOI

2. Tan SJ, Yue J, Hu XC, et al. Nitriding-interface-regulated lithium plating enables flame-retardant electrolytes for high-voltage lithium metal batteries. Angew Chem Int Ed Engl 2019;58:7802-7. DOI PubMed

3. Wang WP, Zhang J, Yin YX, et al. A rational reconfiguration of electrolyte for high-energy and long-life lithium-chalcogen batteries. Adv Mater 2020;32:e2000302. DOI PubMed

4. Lee Y, Fujiki S, Jung C, et al. High-energy long-cycling all-solid-state lithium metal batteries enabled by silver-carbon composite anodes. Nat Energy 2020;5:299-308. DOI

5. Chen X, Shang M, Niu J. Pre-solid electrolyte interphase-covered Li metal anode with improved electro-chemo-mechanical reliability in high-energy-density batteries. ACS Appl Mater Interfaces 2021;13:34064-73. DOI PubMed

6. Guo Z, Pang Y, Xia S, et al. Uniform and anisotropic solid electrolyte membrane enables superior solid-state Li metal batteries. $A d v$ Sci (Weinh) 2021;8:e2100899. DOI PubMed PMC

7. Wang L, Jin Z, Ban X, et al. Lithiophilic nio nanoarrays-modified Ni skeletons with vertical channels for high-loading Li metal batteries. J Electrochem Soc 2021;168:050536. DOI

8. Pathak R, Chen K, Wu F, et al. Advanced strategies for the development of porous carbon as a Li host/current collector for lithium metal batteries. Energy Storage Materials 2021;41:448-65. DOI

9. $\mathrm{Lu} \mathrm{R}$, Zhang B, Cheng Y, et al. Dual-regulation of ions/electrons in a $3 \mathrm{D} \mathrm{Cu}-\mathrm{Cu}_{\mathrm{x}} \mathrm{O}$ host to guide uniform lithium growth for highperformance lithium metal anodes. J Mater Chem A 2021;9:10393-403. DOI

10. Cha E, Yun JH, Ponraj R, Kim DK. A mechanistic review of lithiophilic materials: resolving lithium dendrites and advancing lithium metal-based batteries. Mater Chem Front 2021;5:6294-314. DOI

11. Yan K, Lu Z, Lee H, et al. Selective deposition and stable encapsulation of lithium through heterogeneous seeded growth. Nat Energy 2016;1:16010. DOI

12. Chen XR, Zhao BC, Yan C, Zhang Q. Review on Li deposition in working batteries: from nucleation to early growth. Adv Mater 2021;33:e2004128. DOI PubMed

13. Wang D, Liu H, Liu F, et al. Phase-separation-induced porous lithiophilic polymer coating for high-efficiency lithium metal batteries. Nano Lett 2021;21:4757-64. DOI PubMed

14. Wenzel RN. Resistance of solid surfaces to wetting by water. Ind Eng Chem 1936;28:988-94. DOI

15. Su B, Tian Y, Jiang L. Bioinspired interfaces with superwettability: from materials to chemistry. J Am Chem Soc 2016;138:1727-48. DOI PubMed

16. Quéré D. Wetting and roughness. Annu Rev Mater Res 2008;38:71-99. DOI

17. Wang J, Wang H, Xie J, et al. Fundamental study on the wetting property of liquid lithium. Energy Storage Materials 2018;14:345-50. DOI

18. Luo W, Gong Y, Zhu Y, et al. Reducing interfacial resistance between garnet-structured solid-state electrolyte and Li-metal anode by a germanium layer. Adv Mater 2017;29:1606042. DOI PubMed

19. Zhang Y, Liu B, Hitz E, et al. A carbon-based 3D current collector with surface protection for Li metal anode. Nano Res 2017; 10:1356-65. DOI

20. Fu KK, Gong Y, Fu Z, et al. Transient behavior of the metal interface in lithium metal-garnet batteries. Angew Chem Int Ed Engl 2017;56:14942-7. DOI PubMed

21. Liu B, Gong Y, Fu K, et al. Garnet solid electrolyte protected Li-metal batteries. ACS Appl Mater Interfaces 2017;9:18809-15. DOI PubMed

22. Wang C, Gong Y, Liu B, et al. Conformal, nanoscale $\mathrm{ZnO}$ surface modification of garnet-based solid-state electrolyte for lithium metal anodes. Nano Lett 2017; 17:565-71. DOI PubMed

23. Fu KK, Gong Y, Liu B, et al. Toward garnet electrolyte-based Li metal batteries: An ultrathin, highly effective, artificial solid-state electrolyte/metallic Li interface. Sci Adv 2017;3:e1601659. DOI PubMed PMC

24. Lin D, Liu Y, Cui Y. Reviving the lithium metal anode for high-energy batteries. Nat Nanotechnol 2017;12:194-206. DOI PubMed

25. Chen L, Connell JG, Nie A, et al. Lithium metal protected by atomic layer deposition metal oxide for high performance anodes. $J$ 
Mater Chem A 2017;5:12297-309. DOI

26. Li NW, Yin YX, Li JY, Zhang CH, Guo YG. Passivation of lithium metal anode via hybrid ionic liquid electrolyte toward stable Li plating/stripping. Adv Sci (Weinh) 2017;4:1600400. DOI PubMed PMC

27. Yan C, Cheng XB, Tian Y, et al. Dual-layered film protected lithium metal anode to enable dendrite-free lithium deposition. $A d v$ Mater 2018;30:e1707629. DOI PubMed

28. Fan X, Chen L, Borodin O, et al. Non-flammable electrolyte enables Li-metal batteries with aggressive cathode chemistries. Nat Nanotechnol 2018;13:715-22. DOI PubMed

29. Tan S, Wang W, Tian Y, Xin S, Guo Y. Advanced electrolytes enabling safe and stable rechargeable Li-metal batteries: progress and prospects. Adv Funct Mater 2021;31:2105253. DOI

30. Kwon B, Ha S, Kim D, Koo D, Lee J, Lee KT. Electrochemically active red P/BaTiO ${ }_{3}$-based protective layers suppressing Li dendrite growth for Li metal batteries. Adv Mater Interfaces 2020;7:2001037. DOI

31. Kim Y, Koo D, Ha S, et al. Two-dimensional phosphorene-derived protective layers on a lithium metal anode for lithium-oxygen batteries. ACS Nano 2018;12:4419-30. DOI PubMed

32. Li NW, Yin YX, Yang CP, Guo YG. An artificial solid electrolyte interphase layer for stable lithium metal anodes. Adv Mater 2016;28:1853-8. DOI PubMed

33. Guo H, Hou G, Guo J, et al. Enhanced cycling performance of $\mathrm{Li}-\mathrm{O}_{2}$ battery by using a $\mathrm{Li}_{3} \mathrm{PO}_{4}$-protected lithium anode in DMSObased electrolyte. ACS Appl Energy Mater 2018;1:5511-7. DOI

34. Pang Q, Liang X, Shyamsunder A, Nazar LF. An in vivo formed solid electrolyte surface layer enables stable plating of Li metal. Joule 2017;1:871-86. DOI

35. Gao Y, Zhao Y, Li YC, Huang Q, Mallouk TE, Wang D. Interfacial chemistry regulation via a skin-grafting strategy enables highperformance lithium-metal batteries. J Am Chem Soc 2017;139:15288-91. DOI PubMed

36. Li NW, Shi Y, Yin YX, et al. A flexible solid electrolyte interphase layer for long-life lithium metal anodes. Angew Chem Int Ed Engl 2018;57:1505-9. DOI PubMed

37. Hu Z, Zhang S, Dong S, et al. Poly(ethyl $\alpha$-cyanoacrylate)-based artificial solid electrolyte interphase layer for enhanced interface stability of Li metal anodes. Chem Mater 2017;29:4682-9. DOI

38. Jin Q, Zhang X, Gao H, Li L, Zhang Z. Novel $\mathrm{Li}_{\mathrm{x}} \mathrm{SiS}_{\mathrm{y}} /$ Nafion as an artificial SEI film to enable dendrite-free Li metal anodes and high stability Li-S batteries. J Mater Chem A 2020;8:8979-88. DOI

39. Liang J, Li X, Zhao Y, et al. An air-stable and dendrite-free Li anode for highly stable all-solid-state sulfide-based Li batteries. $A d v$ Energy Mater 2019;9:1902125. DOI

40. Yan C, Cheng XB, Yao YX, et al. An armored mixed conductor interphase on a dendrite-free lithium-metal anode. Adv Mater 2018;30:e1804461. DOI PubMed

41. Jiang Z, Jin L, Han Z, et al. Facile generation of polymer-alloy hybrid layers for dendrite-free lithium-metal anodes with improved moisture stability. Angew Chem Int Ed Engl 2019;58:11374-8. DOI PubMed

42. Cui Q, Zhang P, Wang J. Electrochemical oxidation of $\mathrm{Li}_{2} \mathrm{O}_{2}$ surface-doped with $\mathrm{Li}_{2} \mathrm{CO}_{3}$. ACS Appl Mater Interfaces 2020;12:662732. DOI PubMed

43. Gireaud L, Grugeon S, Laruelle S, Yrieix B, Tarascon J. Lithium metal stripping/plating mechanisms studies: a metallurgical approach. Electrochem commun 2006;8:1639-49. DOI

44. Tang W, Yin X, Chen Z, Fu W, Loh KP, Zheng GW. Chemically polished lithium metal anode for high energy lithium metal batteries. Energy Storage Materials 2018;14:289-96. DOI

45. Gu Y, Wang WW, Li YJ, et al. Designable ultra-smooth ultra-thin solid-electrolyte interphases of three alkali metal anodes. Nat Commun 2018;9:1339. DOI PubMed PMC

46. Gu Y, Wang W, He J, et al. Electrochemical polishing of lithium metal surface for highly demanding solid-electrolyte interphase. ChemElectroChem 2019;6:181-8. DOI

47. Wang SH, Yue J, Dong W, et al. Tuning wettability of molten lithium via a chemical strategy for lithium metal anodes. Nat Commun 2019;10:4930. DOI PubMed PMC

48. Lin D, Liu Y, Liang Z, et al. Layered reduced graphene oxide with nanoscale interlayer gaps as a stable host for lithium metal anodes. Nat Nanotechnol 2016;11:626-32. DOI PubMed

49. Liang Z, Lin D, Zhao J, et al. Composite lithium metal anode by melt infusion of lithium into a 3D conducting scaffold with lithiophilic coating. Proc Natl Acad Sci U S A 2016;113:2862-7. DOI PubMed PMC

50. Zhang Y, Luo W, Wang C, et al. High-capacity, low-tortuosity, and channel-guided lithium metal anode. Proc Natl Acad Sci U S A 2017;114:3584-9. DOI PubMed PMC

51. Liu Y, Lin D, Liang Z, Zhao J, Yan K, Cui Y. Lithium-coated polymeric matrix as a minimum volume-change and dendrite-free lithium metal anode. Nat Commun 2016;7:10992. DOI PubMed PMC

52. Fan L, Li S, Liu L, et al. Enabling stable lithium metal anode via 3D inorganic skeleton with superlithiophilic interphase. Adv Energy Mater 2018;8:1802350. DOI

53. Zhang Y, Wang C, Pastel G, et al. 3D wettable framework for dendrite-free alkali metal anodes. Adv Energy Mater 2018;8:1800635. DOI

54. Zhang R, Chen X, Shen X, et al. Coralloid carbon fiber-based composite lithium anode for robust lithium metal batteries. Joule 2018;2:764-77. DOI

55. Xu Y, Li T, Wang L, Kang Y. Interlayered dendrite-free lithium plating for high-performance lithium-metal batteries. Adv Mater 2019;31:e1901662. DOI PubMed 
56. Duan H, Zhang J, Chen X, et al. Uniform nucleation of lithium in 3D current collectors via bromide intermediates for stable cycling lithium metal batteries. J Am Chem Soc 2018;140:18051-7. DOI PubMed

57. Zhang R, Chen XR, Chen X, et al. Lithiophilic sites in doped graphene guide uniform lithium nucleation for dendrite-free lithium metal anodes. Angew Chem Int Ed Engl 2017;56:7764-8. DOI PubMed

58. Chen X, Chen XR, Hou TZ, et al. Lithiophilicity chemistry of heteroatom-doped carbon to guide uniform lithium nucleation in lithium metal anodes. Sci Adv 2019;5:eaau7728. DOI PubMed PMC

59. Li K, Hu Z, Ma J, Chen S, Mu D, Zhang J. A 3D and stable lithium anode for high-performance lithium-iodine batteries. Adv Mater 2019;31:e1902399. DOI PubMed

60. Ye H, Zheng ZJ, Yao HR, et al. Guiding uniform Li plating/stripping through lithium-aluminum alloying medium for long-life Li metal batteries. Angew Chem Int Ed Engl 2019;58:1094-9. DOI PubMed

61. Wu C, Huang H, Lu W, et al. Mg doped Li-LiB alloy with in situ formed lithiophilic LiB skeleton for lithium metal batteries. Adv Sci (Weinh) 2020;7:1902643. DOI PubMed PMC

62. Wei C, Tan L, Tao Y, et al. Interfacial passivation by room-temperature liquid metal enabling stable 5 V-class lithium-metal batteries in commercial carbonate-based electrolyte. Energy Storage Materials 2021;34:12-21. DOI

63. Ma Q, Zeng X, Yue J, et al. Viscoelastic and nonflammable interface design-enabled dendrite-free and safe solid lithium metal batteries. Adv Energy Mater 2019;9:1803854. DOI

64. Wang Z, Tan R, Wang H, et al. A metal-organic-framework-based electrolyte with nanowetted interfaces for high-energy-density solid-state lithium battery. Adv Mater 2018;30:1704436. DOI PubMed

65. Zhang Z, Zhang L, Liu Y, et al. Interface-engineered $\mathrm{Li}_{7} \mathrm{La}_{3} \mathrm{Zr}_{2} \mathrm{O}_{12}$-based garnet solid electrolytes with suppressed Li-dendrite formation and enhanced electrochemical performance. ChemSusChem 2018;11:3774-82. DOI

66. Zeng X, Yin Y, Shi Y, et al. Lithiation-derived repellent toward lithium anode safeguard in quasi-solid batteries. Chem 2018;4:298307. DOI

67. Fan W, Li NW, Zhang X, et al. A dual-salt gel polymer electrolyte with 3D cross-linked polymer network for dendrite-free lithium metal batteries. Adv Sci (Weinh) 2018;5:1800559. DOI PubMed PMC

68. Zuo TT, Shi Y, Wu XW, et al. Constructing a stable lithium metal-gel electrolyte interface for quasi-solid-state lithium batteries. ACS Appl Mater Interfaces 2018;10:30065-70. DOI PubMed

69. Zhou W, Wang S, Li Y, Xin S, Manthiram A, Goodenough JB. Plating a dendrite-free lithium anode with a polymer/ceramic/polymer sandwich electrolyte. J Am Chem Soc 2016;138:9385-8. DOI PubMed

70. Hartmann P, Leichtweiss T, Busche MR, et al. Degradation of NASICON-type materials in contact with lithium metal: formation of mixed conducting interphases (MCI) on solid electrolytes. J Phys Chem C 2013;117:21064-74. DOI

71. Duan H, Fan M, Chen WP, et al. Extended electrochemical window of solid electrolytes via heterogeneous multilayered structure for high-voltage lithium metal batteries. Adv Mater 2019;31:e1807789. DOI PubMed

72. Duan H, Yin YX, Shi Y, et al. Dendrite-free Li-metal battery enabled by a thin asymmetric solid electrolyte with engineered layers. $J$ Am Chem Soc 2018;140:82-5. DOI PubMed

73. Liang JY, Zeng XX, Zhang XD, et al. Engineering Janus interfaces of ceramic electrolyte via distinct functional polymers for stable high-voltage Li-metal batteries. J Am Chem Soc 2019;141:9165-9. DOI PubMed

74. Li M, Frerichs JE, Kolek M, et al. Solid-state lithium-sulfur battery enabled by Thio-LiSICON/polymer composite electrolyte and sulfurized polyacrylonitrile cathode. Adv Funct Mater 2020;30:1910123. DOI

75. Wang C, Xie H, Zhang L, et al. Universal soldering of lithium and sodium alloys on various substrates for batteries. Adv Energy Mater 2018;8:1701963. DOI

76. Duan J, Wu W, Nolan AM, et al. Lithium-graphite paste: an interface compatible anode for solid-state batteries. Adv Mater 2019;31:e1807243. DOI PubMed

77. Zheng H, Wu S, Tian R, et al. Intrinsic lithiophilicity of Li-garnet electrolytes enabling high-rate lithium cycling. Adv Funct Mater 2019;30:1906189. DOI

78. Luo W, Gong Y, Zhu Y, et al. Transition from superlithiophobicity to superlithiophilicity of garnet solid-state electrolyte. J Am Chem Soc 2016;138:12258-62. DOI PubMed

79. Lu Y, Huang X, Ruan Y, et al. An in situ element permeation constructed high endurance Li-LLZO interface at high current densities. J Mater Chem A 2018;6:18853-8. DOI

80. Yan M, Liang J, Zuo T, et al. Stabilizing polymer-lithium interface in a rechargeable solid battery. Adv Funct Mater 2019;30:1908047. DOI

81. Ruan Y, Lu Y, Huang X, et al. Acid induced conversion towards a robust and lithiophilic interface for $\mathrm{Li}_{-} \mathrm{Li}_{7} \mathrm{La}_{3} \mathrm{Zr}_{2} \mathrm{O}_{12}$ solid-state batteries. J Mater Chem A 2019;7:14565-74. DOI

82. Alexander GV, Indu M, Kamakshy S, Murugan R. Development of stable and conductive interface between garnet structured solid electrolyte and lithium metal anode for high performance solid-state battery. Electrochimica Acta 2020;332:135511. DOI

83. Cui C, Yang C, Eidson N, et al. A highly reversible, dendrite-free lithium metal anode enabled by a lithium-fluoride-enriched interphase. Adv Mater 2020;32:e1906427. DOI PubMed

84. Fan X, Ji X, Han F, et al. Fluorinated solid electrolyte interphase enables highly reversible solid-state Li metal battery. Sci Adv 2018;4:eaau9245. DOI PubMed PMC

85. Xu R, Han F, Ji X, Fan X, Tu J, Wang C. Interface engineering of sulfide electrolytes for all-solid-state lithium batteries. Nano Energy 2018;53:958-66. DOI

86. Xu H, Li Y, Zhou A, et al. $\mathrm{Li}_{3} \mathrm{~N}$-modified garnet electrolyte for all-solid-state lithium metal batteries operated at $40{ }^{\circ} \mathrm{C}$. Nano Lett 
2018;18:7414-8. DOI PubMed

87. Tian Y, Ding F, Zhong H, et al. $\mathrm{Li}_{6.75} \mathrm{La}_{3} \mathrm{Zr}_{1.75} \mathrm{Ta}_{0.25} \mathrm{O}_{12} @$ amorphous $\mathrm{Li}_{3} \mathrm{OCl}$ composite electrolyte for solid state lithium-metal batteries. Energy Storage Materials 2018;14:49-57. DOI 